\title{
BMJ Open Developing an evidence assessment framework and appraising the academic literature on migrant health in Malaysia: a scoping review
}

\author{
Allard Willem de Smalen (D) , ${ }^{1,2,3}$ Zhie X Chan, ${ }^{3}$ Claudia Abreu Lopes, ${ }^{3}$ \\ Michaella Vanore, ${ }^{1,2}$ Tharani Loganathan (D) , ${ }^{4}$ Nicola S Pocock (D) ${ }^{3,5}$
}

To cite: de Smalen AW, Chan ZX, Abreu Lopes C et al. Developing an evidence assessment framework and appraising the academic literature on migrant health in Malaysia: a scoping review. BMJ Open 2021;11:e041379. doi:10.1136/ bmjopen-2020-041379

- Prepublication history and additional material for this paper is available online. To view these files, please visit the journal online (http://dx.doi.org/10. 1136/bmjopen-2020-041379)

Received 09 June 2020 Revised 02 December 2020 Accepted 09 December 2020

Check for updates

(C) Author(s) (or their employer(s)) 2021. Re-use permitted under CC BY-NC. No commercial re-use. See rights and permissions. Published by BMJ.

For numbered affiliations see end of article.

Correspondence to

Mr Allard Willem de Smalen; allarddesmalen@gmail.com

\section{ABSTRACT}

Background A large number of international migrants in Malaysia face challenges in obtaining good health, the extent of which is still relatively unknown. This study aims to map the existing academic literature on migrant health in Malaysia and to provide an overview of the topical coverage, quality and level of evidence of these scientific studies.

Methods A scoping review was conducted using six databases, including Econlit, Embase, Global Health, Medline, PsycINFO and Social Policy and Practice. Studies were eligible for inclusion if they were conducted in Malaysia, peer-reviewed, focused on a health dimension according to the Bay Area Regional Health Inequities Initiative (BARHII) framework, and targeted the vulnerable international migrant population. Data were extracted by using the BARHII framework and a newly developed decision tree to identify the type of study design and corresponding level of evidence. Modified Joanna Briggs Institute checklists were used to assess study quality, and a multiple-correspondence analysis (MCA) was conducted to identify associations between different variables.

Results 67 publications met the selection criteria and were included in the study. The majority $(n=41)$ of studies included foreign workers. Over two-thirds $(n=46)$ focused on disease and injury, and a similar number $(n=46)$ had descriptive designs. The average quality of the papers was low, yet quality differed significantly among them. The MCA showed that high-quality studies were mostly qualitative designs that included refugees and focused on living conditions, while prevalence and analytical crosssectional studies were mostly of low quality.

Conclusion This study provides an overview of the scientific literature on migrant health in Malaysia published between 1965 and 2019. In general, the quality of these studies is low, and various health dimensions have not been thoroughly researched. Therefore, researchers should address these issues to improve the evidence base to support policy-makers with high-quality evidence for decision-making.

\section{INTRODUCTION}

Worldwide, the international migrant population accounts for approximately 272 million people, with almost one-third within Asia. ${ }^{1}$
Strengths and limitations of this study

- This study provides a comprehensive overview of migrant health research in Malaysia, including a summary table, critical assessment tables and a multiple-correspondence analysis.

- Methodological contributions by creating an evidence assessment framework, including a decision tree that identifies the type of study design and corresponding level of evidence, and modified Joanna Briggs Institute checklists.

- Exclusive focus on vulnerable migrants within the non-citizen population in Malaysia.

- Only English peer-reviewed academic articles were included in this study, and, therefore, much relevant information that could potentially be used to inform both policies and practice may have been excluded from this review.

Due to its strategic geographical location and high labour demand, Malaysia is among the top destination countries for international migrants in the Asian region. ${ }^{2}$ According to the Department of Statistics Malaysia (DOSM), the documented non-citizen population represented 3.2 million people in 2019, which accounts for $10 \%$ of Malaysia's total population. ${ }^{3}$ DOSM defines a non-citizen as a person that resides in Malaysia for 6 months or more in the reference year. ${ }^{4}$ However, no subcategories were included in this definition. According to the Office of the United Nations High Commissioner for Human Rights, a non-citizen is an individual that does not have an effective connection with the location where the person is situated according to the host nation, and includes various types of migrants, such as foreigners with permanent residency, refugees, asylum seekers, foreign labour, international students, stateless individuals and victims of human trafficking. ${ }^{5}$ Other 
Table 1 Definitions of migrant-related terms

\begin{tabular}{|c|c|}
\hline Term & Definition \\
\hline $\begin{array}{l}\text { Regular migrant worker (documented or } \\
\text { legal migrant worker) }\end{array}$ & $\begin{array}{l}\text { 'A migrant worker or members of his or her family authorised to enter, to stay and to } \\
\text { engage in a remunerated activity in the State of employment pursuant to the law of } \\
\text { that State and to international agreements to which that State is a party. }{ }^{116} \text { (p29) }\end{array}$ \\
\hline $\begin{array}{l}\text { Irregular migrant worker (undocumented } \\
\text { or illegal migrant worker) }\end{array}$ & $\begin{array}{l}\text { 'Migrant workers or members of their families, who are not authorised to enter, to } \\
\text { stay or to engage in employment in a State. }{ }^{.16}(\mathrm{p} 102)\end{array}$ \\
\hline Refugee & $\begin{array}{l}\text { 'A person who, owing to a well-founded fear of persecution for reasons of race, } \\
\text { religion, nationality, membership of a particular social group or political opinions, is } \\
\text { outside the country of his nationality and is unable or, owing to such fear, is unwilling } \\
\text { avail himself of the protection of that country.'116 (p79) }\end{array}$ \\
\hline Asylum seeker & $\begin{array}{l}\text { 'A person who seeks safety from persecutions or serious harm in a country other } \\
\text { than his or her own and awaits a decision on the application for refugee status under } \\
\text { relevant international and national instruments. In case of a negative decision, the } \\
\text { person must leave the country and may be expelled, as may any non-national in an } \\
\text { irregular or unlawful situation, unless permission to stay is provided on humanitarian } \\
\text { or other related grounds.' }{ }^{116} \text { (p12) }\end{array}$ \\
\hline
\end{tabular}

definitions of migrant-related terms that are used in this paper are presented in table 1 .

The vast majority of non-citizens in Malaysia are migrant workers, where foreign labour can be divided according to their visa status into regular and irregular migrant workers. According to the Ministry of Home Affairs, Malaysia issued 2 million work permits to documented migrant workers in 2019. ${ }^{6}$ However, the total number of migrant workers, both documented and undocumented, is estimated to fall between 4.2 and 6.2 million people. ${ }^{2}$ Another group that contributes significantly to the noncitizen population in Malaysia is refugees and asylum seekers. The terms refugees and asylum seekers are often used interchangeably, yet, these populations differ by their legal status in destination countries and subsequent vulnerabilities (see definitions in table 1). In 2019, an approximate 178580 refugees and asylum seekers were registered with the United Nations High Commissioner for Refugees in Malaysia, where 153770 (86\%) came from Myanmar. The remaining number (14\%) came from Yemen, Syria, Afghanistan, Iraq, Palestine, Pakistan, Sri Lanka, Somalia and other countries. ${ }^{7}$

Refugees, asylum seekers and both documented and undocumented low-skilled foreign workers can be classified as vulnerable migrants in Malaysia, as these populations may face significant hardships in their new country of residence. ${ }^{89}$ Vulnerable migrants are more prone to being exploited and abused, have an increased need to be protected by duty bearers and are not able to fully benefit from their human rights. ${ }^{10}$ Health is among these affected human rights, as migrant workers and refugees could encounter various challenges to maintain proper health and prevent poor health outcomes, including difficulties in accessing healthcare and obtaining quality health services. ${ }^{10-12}$ According to Sweileh et al, ${ }^{13}$ assessing the current status of scientific output and identifying research gaps could positively contribute towards improving the evidence base for advocating for migrant health needs. Scoping reviews can be helpful to map the academic literature and have been used by different researchers to present the available evidence on migrant health issues in other countries. ${ }^{1415}$

Despite the burgeoning academic literature on migrant health in Malaysia, health information on migrant-related issues is still limited, and public data remain difficult to access. Aggravating the matter, there is no overall picture currently available of the evidence base on migrant health in Malaysia, including critical appraisal of the quality of research. Therefore, this study aims to map the existing academic literature on migrant health in Malaysia since 1965 to identify the trends and gaps in this field, as well as to present an overview of the topical coverage, quality and level of evidence of these scientific studies.

\section{METHODS}

\section{General methods}

A scoping review was conducted, following the Preferred Reporting Items for Systematic Reviews and MetaAnalyses-Extension for Scoping Reviews guidelines ${ }^{16}$ (online supplemental file 1). A prereview protocol was developed to guide decisions for literature selection and structure of the review, and included the review question, aim, search strategy, selection criteria and risk of bias assessment. However, the protocol was not formally registered and changed to some extent over the course of this review. The prereview protocol can be accessed on request from the first author. Data were extracted and organised using the Bay Area Regional Health Inequities Initiative (BARHII) framework. ${ }^{17}$ In addition, a decision tree was developed to classify the type of study design and level of evidence of each journal article. Subsequently, a quality assessment of the included literature was conducted by using the Joanna Briggs Institute (JBI) critical appraisal toolkit. ${ }^{18}$ Lastly, the data were analysed, and a multiplecorrespondence analysis (MCA) was applied to explore existing relationships between variables, including the 


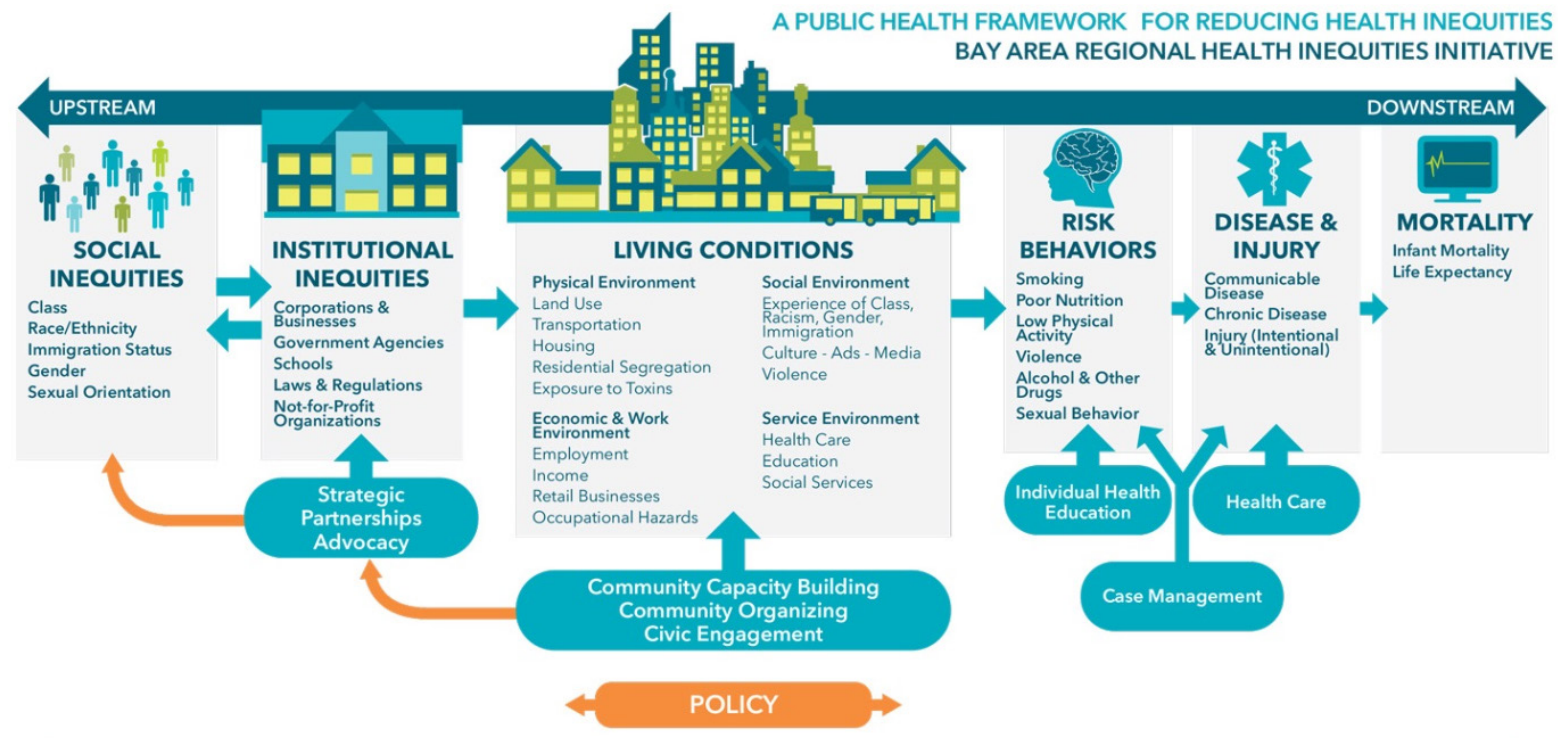

Figure 1 Bay Area Regional Health Inequities Initiative framework.

type of migrant, main health dimension, quality of the study and research design.

\section{Patient and public involvement}

Patients and the public were not involved in this study.

\section{Conceptual framework}

The BARHII framework was used to organise the identified literature in this scoping review into specific factors that shape equitable health outcomes (figure 1). The BARHII framework was selected due to its comprehensive nature and inclusion of various health dimensions, whereas other models focused on specific public health elements or lacked clear explanation regarding the included health-related components of the model. ${ }^{1920}$

The BARHII framework consists of six dimensions: (1) social inequities; (2) institutional inequities; (3) living conditions; (4) risk behaviour; (5) disease and injury; and (6) mortality. In addition, each health dimension contains various subdimensions (as presented in figure 1). Except for 'social inequities,' the other five categories were used to describe which health dimension the particular articles focused on. The social inequities element was incorporated by describing the population of interest, which was divided into three categories: foreign workers, asylum seekers and refugees, and unclassified migrants. The lattermost category was applied if a paper used the term 'migrants' or 'immigrants' but lacked specific information to classify the study population as foreign workers or asylum seekers/refugees.

Institutional inequities include the practices of corporations, businesses, government agencies, schools, notfor-profit organisations as well as laws, regulations and policies that could influence health outcomes (eg, a regulation that obligates companies to financially compensate an individual in case of a work incident).
Living conditions consist of the physical environment (eg, indoor air pollution), economic and work environment (eg, unemployment), social environment (eg, discrimination in the neighbourhood) and service environment (eg, healthcare) that people live in, and that play a role in determining their health outcomes (eg, denied healthcare access due to visa status).

Risk behaviour includes smoking, poor nutrition, low physical activity, violence, alcohol and other drugs and sexual behaviour. This dimension reflects the way someone acts and how that increases or decreases the risk of obtaining a particular health outcome (eg, the attitude and related behaviour towards smoking could influence an individual's level of risk of developing lung cancer).

Disease and injury consist of communicable diseases (also known as infectious diseases; eg, chlamydia), chronic diseases (also known as non-communicable diseases; eg, cancer) and injuries (eg, fractured bone). This dimension describes the number of people or individual cases with a particular health outcome (eg, 10 out of the 100 people suffered from cancer).

Mortality was changed to 'mortality and morbidity' and focused on death and disease rates of the study population (eg, 10 out of 1000 live births of children under the age of 1 died) to distinguish epidemiological studies with larger samples from descriptive studies with smaller samples, where the latter were categorised as disease and injury studies.

Furthermore, some additional subdimensions were created during the data extraction stage, as these were lacking in the original BARHII framework (eg, the subdimension 'mental health' was added to the disease and injury dimension). 


\section{Search strategy}

Based on the guidelines of the London School of Hygiene and Tropical Medicine ${ }^{21}$ and Bramer et $a l^{22}$ on selecting the number and types of databases that should be included in biomedical systematic searches, six databases were selected for this study: Econlit, Embase, Global Health, Medline, PsycINFO and Social Policy and Practice. This scoping review includes studies from 1965 onwards until 2019. However, all identified records were retrieved from the six databases to manually screen the data for publication date-related issues. The search process was conducted by AWdS and included a twostage procedure to ensure that the search was exhaustive and to minimise the risk of missing potentially eligible studies. The first stage focused on identifying Englishlanguage key words and Medical Subject Headings terms for migrants (eg, immigrants, foreign workers, refugees), health (eg, disease, infection, disorder) and Malaysia (eg, Sabah, Kuala Lumpur) through reading search strategies of other review studies on migrant health as well as using medical terminology of renowned medical institutions, such as the Mayo Clinic. Subsequently, these items were combined by using Boolean operators (eg, migrant AND health AND Malaysia) in the search platform of each database (online supplemental file 2).

\section{Selection criteria}

Studies were eligible for inclusion if they met the following inclusion criteria: (1) conducted in Malaysia, including cross-national studies in which Malaysia was included; (2) published in peer-reviewed academic journals; (3) primary outcomes of the study included a health-related variable from at least one of the five health dimensions of the BARHII framework; (4) employment of one of the following study designs: literature synthesis (systematic review, meta-analysis, other scientific review designs), qualitative (interviews, focus group discussions) and/or quantitative (randomised controlled trial (RCT), cohort, case-control, cross-sectional, case series, case report) study design; (5) written in English; (6) inclusion of international (im)migrants, foreign workers, asylum seekers and refugees, as these groups were considered as vulnerable migrant populations in Malaysia. Articles that included both migrants and the general population were included in this study if sufficient information concerning the migrant population was available.

Studies were excluded if they were: (1) conducted or included data from 1965 or earlier, as Singapore was part of Malaysia until 1965, and this study is careful to only include Malaysia studies without Singapore; (2) grey literature; (3) opinion papers, editorials, fieldnotes of symposia, conferences and workshop abstracts; (4) focused on non-citizens and foreigners, where it was unclear whether a vulnerable migrant population was included (such as permanent residents, naturalised persons, expatriates, temporary visitors, tourists, Malaysian returnees and international students); (5) only presented migrants as a control variable and no other information regarding migrants was available.

\section{Data extraction}

Three reviewers (AWdS, ZXC and NSP) were involved in the screening process, where all had experience in the domain of public health and AWdS and NSP had practical knowledge with respect to conducting systematic reviews due to previous research work. Titles and abstracts were exported by AWdS and subsequently moved into Rayyan, an open-source software designed to support systematic reviews. AWdS and $\mathrm{ZXC}$ were the main reviewers, where AWdS conducted an entire screening of titles and abstracts and ZXC assessed a randomly selected $20 \%$ sample. Independent screening was carried out by using the 'blind' function of Rayyan, with both researchers working separately. The first stage involved screening titles and abstracts according to the inclusion criteria. Subsequently, AWdS and ZXC conducted an independent full-text screening of all potential articles and attached comments to each article on why the paper was included or excluded. After each screening stage, AWdS and ZXC compared their findings and discussed the discrepancies. In both stages, the discrepancies were about $13 \%-14 \%$ of the papers and were mostly around the study design and target populations. Conflicts were examined and resolved by NSP.

Following the full-text screening stage, the data were extracted by one reviewer (AWdS) and disaggregated by the different dimensions of the BARHII framework, including the type of migrant (social inequities), main health dimension (institutional inequities, living conditions, risk behaviour, disease and injury and mortality and morbidity) and health subdimensions.

For the next stage, a decision tree was developed to ensure that the correct quality appraisal tool by study design was selected and to identify the level of evidence of the included literature (figure 2). Although various research designs were included in the decision tree, some study designs did not fit in this model, such as the mixedmethod design.

The decision tree built on the study design tree from the Centre for Evidence-Based Medicine ${ }^{23}$ and essentially allowed research of varying designs to be consistently, reliably classified into one of several design families. The newly developed decision tree was created through a two-step process. First, a table was created that included definitions of various research designs, and, subsequently, specific traits of these definitions were used to develop guiding questions for the decision tree (table 2).

Second, Tomlin and Borgetto's ${ }^{24}$ model was used to identify the level of evidence of the included literature, as the study designs that were included in their model were in line with the research designs in the definitions table. In addition, it was one of the few models that deconstructed the single-hierarchy framework and assigned study designs to different categories depending on the study objective (eg, if the study design did not aim 
What type of data has been used?

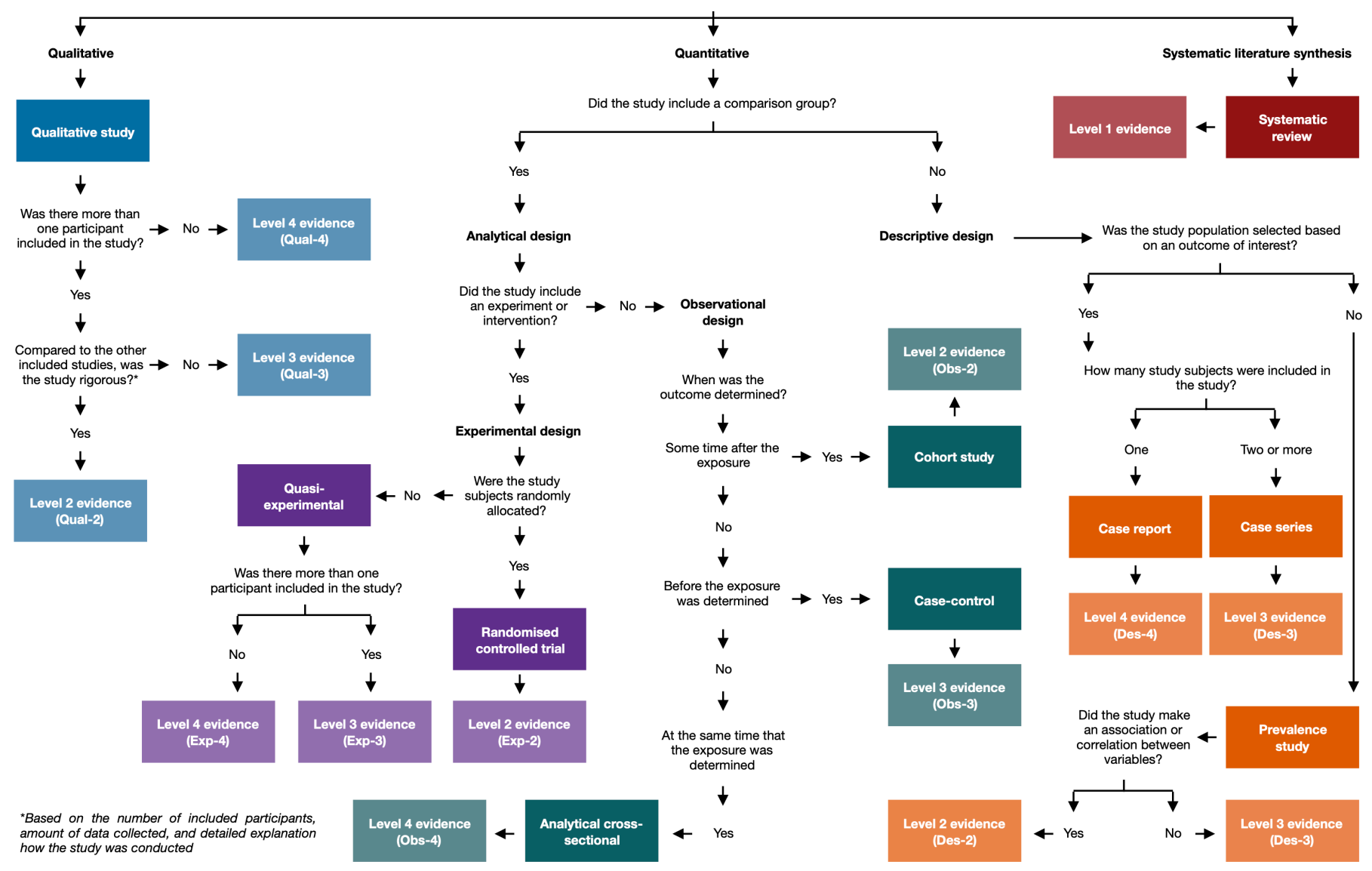

Figure 2 Decision tree to identify the type of study design and corresponding level of evidence.

to provide a causal relationship, but simply describe a particular outcome, the study design would be classified as descriptive research), and, therefore, valued studies with different objectives equally. Tomlin and Borgetto's model consists of four dimensions, including descriptive research, experimental research, outcome research and qualitative research. Each of these dimensions contains four subclasses to show the level of evidence within each class, where level 1 is the highest level of evidence and level 4 the lowest. The assignment of these levels to the different study designs is based on the degree of internal validity/authenticity and external validity/transferability, where level 1 is regarded with the highest level of these two measures and level 4 ranks the lowest. Table 3 shows the different research dimensions that correspond with the included study designs and level of evidence.

After incorporating feedback on the questions used to identify the research design and multiple testing rounds to assess if the questions were specific enough to distinguish these designs within the full set of articles, the final version of the decision tree-as seen in figure 2-was used to extract the data.

\section{Quality appraisal and level of evidence assessment}

The quality assessment of the included studies was conducted by one reviewer (AWdS) based on the JBI critical appraisal tools, as this toolkit includes checklists for a wide variety of study designs that are most in line with the research designs included in this study. Additional objective criteria specific to migrant health studies were developed for each question of the JBI checklists to increase the reliability of the quality assessment. An example is provided in table 4 .

After discussing the additional criteria and piloting the tools, slight modifications were made for the JBI tools, and these final versions were used to assess the quality of the papers. The modified checklists can be accessed on request from the first author.

Questions were answered with 'Yes (V)' if the study met the criteria according to descriptions provided in the final version of the JBI toolkit. 'No/Unclear (X)' was selected if the study did not address the question or if information to assess the given criteria was lacking. The score concerning the quality of the study was determined by summing up all 'Yes' answers and dividing this number by the total number of answered questions, which differed by study design in the JBI tools. Questions that were answered with 'Not applicable (N/A)' were excluded from the calculation. As the JBI toolkit has no standard scoring index, the following scoring system was applied: (1) low quality $=0 \%-50 \%$; (2) moderate quality=above $50 \%$ and below $75 \%$; (3) high quality $=75 \%$ or higher. Although a four-band scoring system-where 
Table 2 Definitions of included study designs

Study design
Analytical studies

Systematic review

Randomised controlled trial (RCT)

Case-control study

$\begin{array}{ll}\text { Analytical cross-sectional } & \begin{array}{l}\text { A study that looks at two groups-exposed and unexposed-and the outcome of interest } \\ \text { at a particular point or period of time to compare the differences between the two } \\ \text { groups. }\end{array} \\ \text { Descriptive studies } & \begin{array}{l}\text { Studies that do not strive to quantify a relationship between variables, but simply } \\ \text { describe the disease outcome and characteristics within a defined population. Note that } \\ \text { descriptive studies can still include analytic components. }\end{array} \\ \text { Prevalence study } & \begin{array}{l}\text { A study that looks at a population at a particular point or period of time to describe the } \\ \text { prevalence of an outcome of interest. }\end{array} \\ \text { Case series } & \begin{array}{l}\text { A study where only subjects are included with a particular outcome of interest to describe } \\ \text { the shared and diverging characteristics of this study population. }\end{array} \\ \text { Case report } & \text { A study that describes an unfamiliar or extraordinary outcome of one individual. }{ }^{120}\end{array}$

each category would include a $25 \%$ scoring range-was considered, a three-band scoring system was selected because the three given categories-low, moderate and high-would simplify the interpretation concerning the quality of the study. In a four-band system, the distinction and classification of the two middle categories are less straightforward compared with the three-band scoring system. Further, the first two categories in a four-band scoring system would still represent a poor-quality study, and, hence, should be used to signal more cautious interpretation of the study results among readers. The cut-off score was based on the idea that if a study could answer yes to only half or less of the questions, it would not be sufficient to transmit a reliable message to the audience. Therefore, at least more than half of the questions should be answered with yes to obtain a moderate score. The $75 \%$ cut-off was still based on the idea of having four equal scoring categories, where $75 \%$ and above would be classified as a high-quality study and would inform the audience with a more credible message.

\section{Data analysis}

Data concerning the type of migrant, health dimension, health subdimension, research design, level of evidence and quality assessment score were imported into Microsoft Excel for Mac (V.16.28). Mean quality scores were calculated for the different variables by using Microsoft Excel, including the type of migrant, health dimension, health subdimension, research design and level of evidence. RStudio (V.1.0.136; Macintosh; Intel Mac OS X 10_15) was used to conduct $\chi^{2}$ tests and an MCA. An MCA is a descriptive technique that can be used to visually demonstrate relationships among the levels of several categorical variables-here, these include the type of migrant, main health dimension, quality of the study and research design-in a two-dimensional (2D) space. The MCA projects categories in a 2D space with axes defined by latent dimensions (and, therefore, it is not possible to label the axes), based on weighted Euclidean distances. ${ }^{25}$ The MCA allows categories with similar profiles to be grouped together, where a closer 
Table 3 Level of evidence for each study design

\begin{tabular}{|c|c|c|}
\hline Research design* & Level of evidence & Abbreviation \\
\hline \multicolumn{3}{|l|}{ Descriptive research } \\
\hline Systematic review of descriptive studies & 1 & Des-1 \\
\hline Case series and prevalence study without analytical component & 3 & Des-3 \\
\hline Case report & 4 & Des-4 \\
\hline Systematic review/meta-analysis of experimental studies & 1 & Exp-1 \\
\hline Randomised controlled trial & 2 & Exp-2 \\
\hline Group quasi-experimental study (a.k.a. non-RCT) & 3 & Exp-3 \\
\hline Quasi-experimental study with single subject & 4 & Exp-4 \\
\hline \multicolumn{3}{|l|}{ Observational research } \\
\hline Case-control & 3 & Obs-3 \\
\hline Analytical cross-sectional study & 4 & Obs-4 \\
\hline \multicolumn{3}{|l|}{ Qualitative research } \\
\hline Systematic review/meta-synthesis of qualitative studies & 1 & Qual-1 \\
\hline Group qualitative studies with more rigour & 2 & Qual-2 \\
\hline Group qualitative studies with less rigour & 3 & Qual-3 \\
\hline Qualitative study with a single informant & 4 & Qual-4 \\
\hline
\end{tabular}

1=Highest level of evidence; $4=$ lowest level of evidence.

*The following terminology of Tomlin and Borgetto's model has been modified to align with the included research designs in this study: association/correlation studies=prevalence studies with analytical component; normative/descriptive studies=prevalence studies without analytical component; individual case studies=case report; controlled-clinical trials=group quasi-experimental study; single-subject studies=quasi-experimental study with single subject; pre-existing groups comparisons with covariate analysis=cohort study; one-group prepost studies=analytical cross-sectional study.

†Rigour was subjectively assessed and based on the number of included participants, amount of collected data and detailed explanation how the study was conducted.

$\mathrm{RCT}$, randomised controlled trial.

distance of categories within the same quadrant demonstrates a stronger relationship, whereas categories that are further apart and in opposite quadrants present weaker associations. ${ }^{26}$ In addition to the MCA, $\chi^{2}$ tests were conducted to assess whether categorical variables were independent (eg, not associated). It should be noted that a few studies included two BARHII dimensions, yet, the analysis only allowed one dimension to be included. Therefore, only the most prominent dimension, based on the amount of attention given to the specific dimension in the article, was selected and used for the analysis.

Table 4 Example of additional objective criteria for the Joanna Briggs Institute toolkit

Question 'Were the study subjects and the setting described in detail?'121 (p3)

Original explanation 'The study sample should be described in sufficient detail so that other researchers can determine if it is comparable to the population of interest to them. The authors should provide a clear description of the population from which the study participants were selected or recruited, including demographics, location, and time period. ${ }^{, 121}(\mathrm{p} 4)$

Additional objective 'Yes' should be selected if different demographic variables are presented in absolute numbers, criteria including age (aggregated in individual years or age categories), sex, and nationality. In addition, the setting should be described by providing the name of the location and/or a description of the location. 'No/unclear' should be selected if a description regarding age, sex, and/or nationality in absolute numbers are lacking. Note that using only means and ratios will not be sufficient to answer this question, and no/unclear should be selected. In addition, no/unclear should be selected if the name and/or description of the location is not given. 

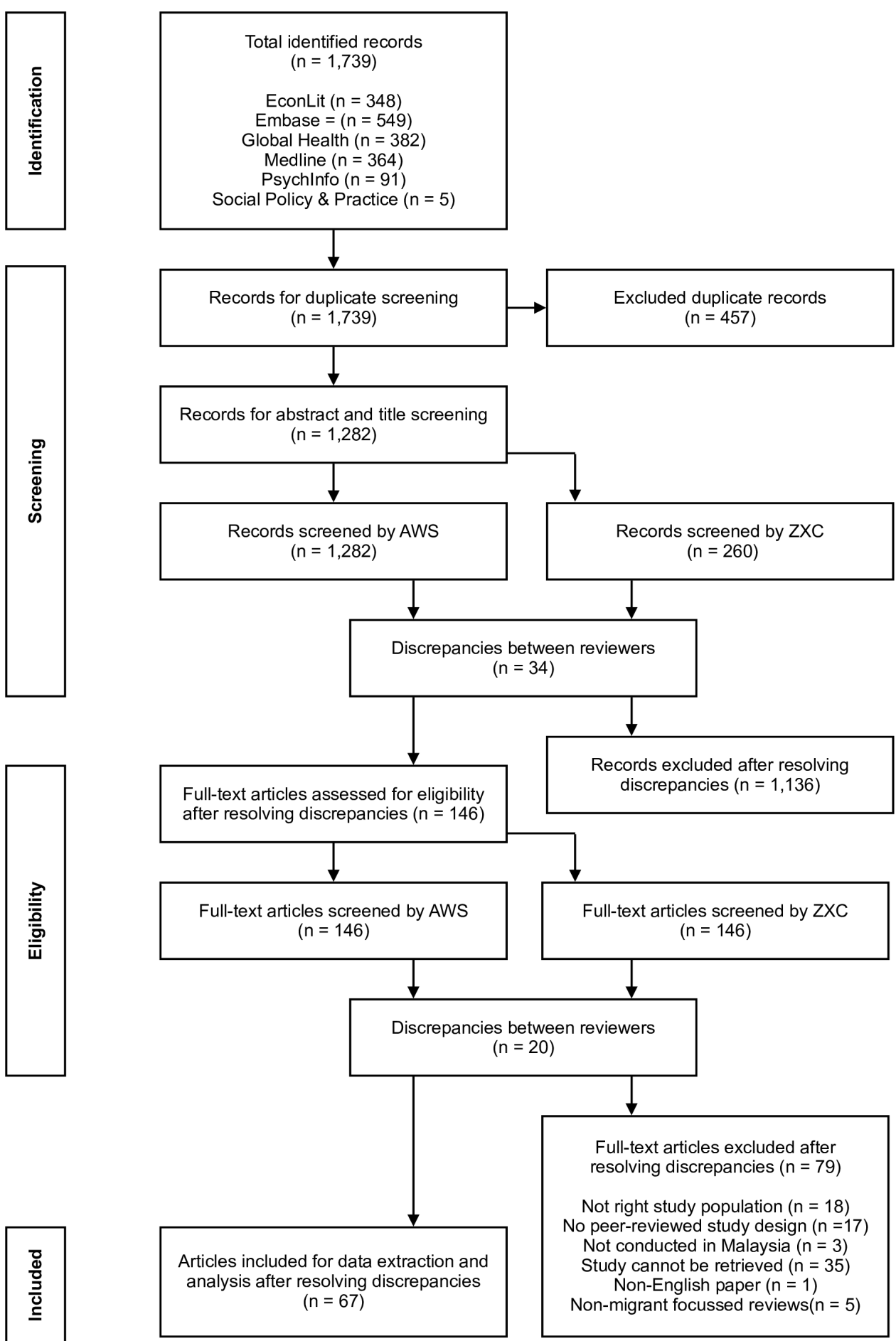

Figure 3 Flow chart of the data selection process.

\section{RESULTS}

The study selection process is presented in figure 3. After removing the duplicates, 1282 original records were identified. A total of 1136 papers were excluded after the title and abstract screening stage due to focusing on another population of interest, lacking focus on a BARHII health dimension, not being a peer-reviewed academic article, and including data before 1965. As a result, 146 articles were eligible for the full-text screening stage. Subsequently, full-text articles were retrieved from these 146 records, and eventually, 67 papers met the inclusion criteria and were included in this review.

\section{Characteristics of included papers}

This section first demonstrates the findings of each BARHII dimension, followed by the results on the quality and level of evidence of the included studies. Lastly, existing relationships between the type of study design, study quality of the study, type of migrant and main health dimension are shown. Table 5 presents a descriptive 


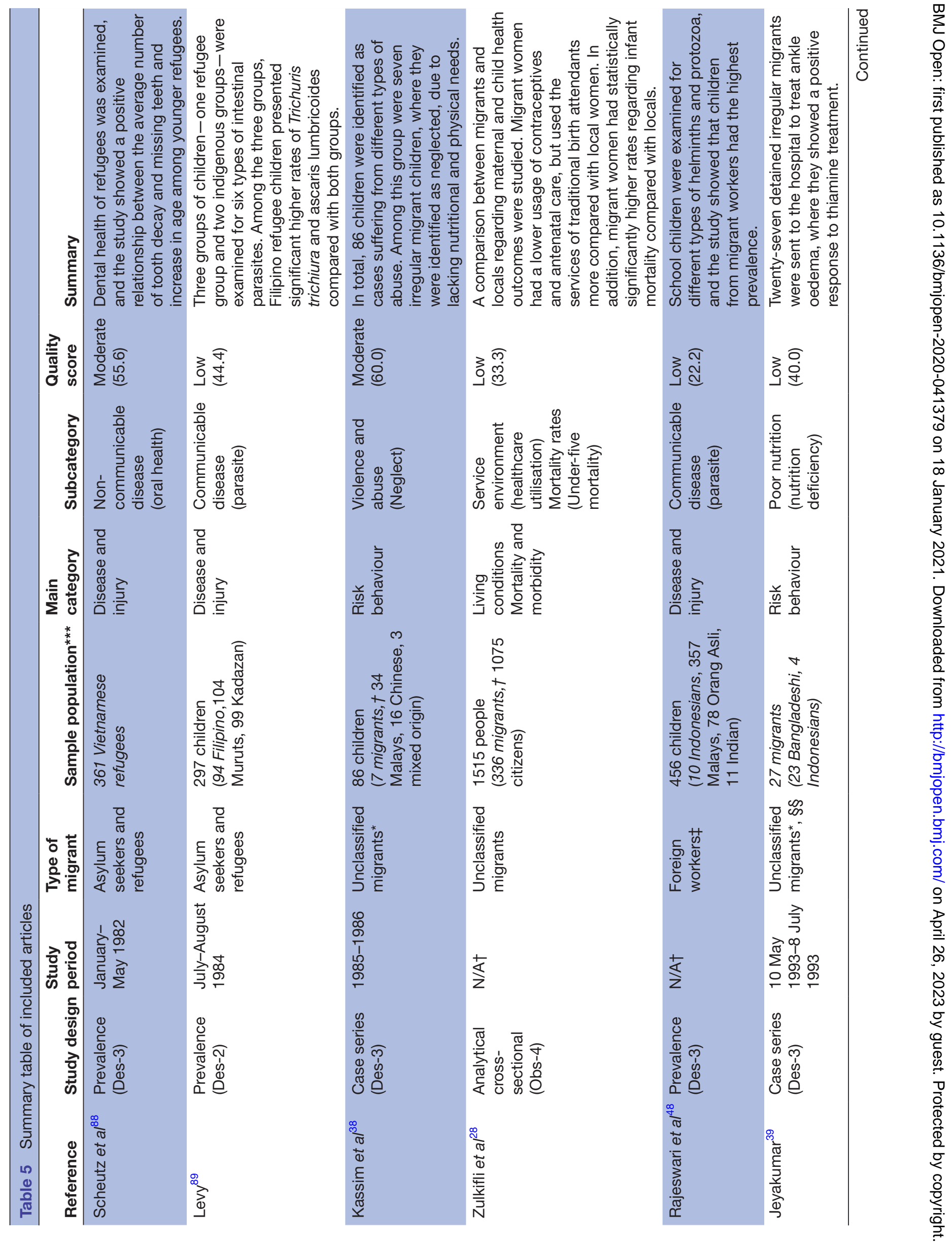




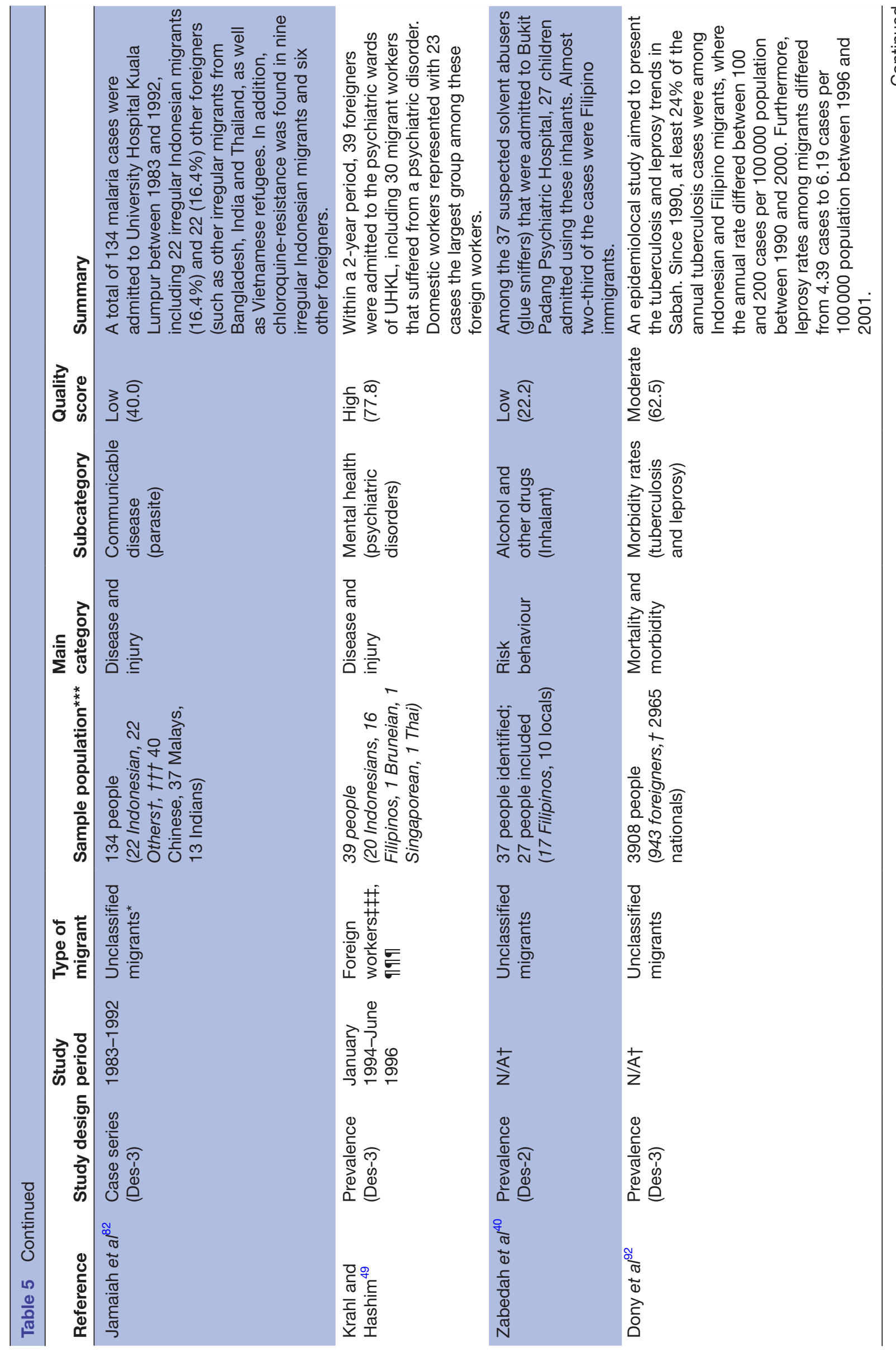




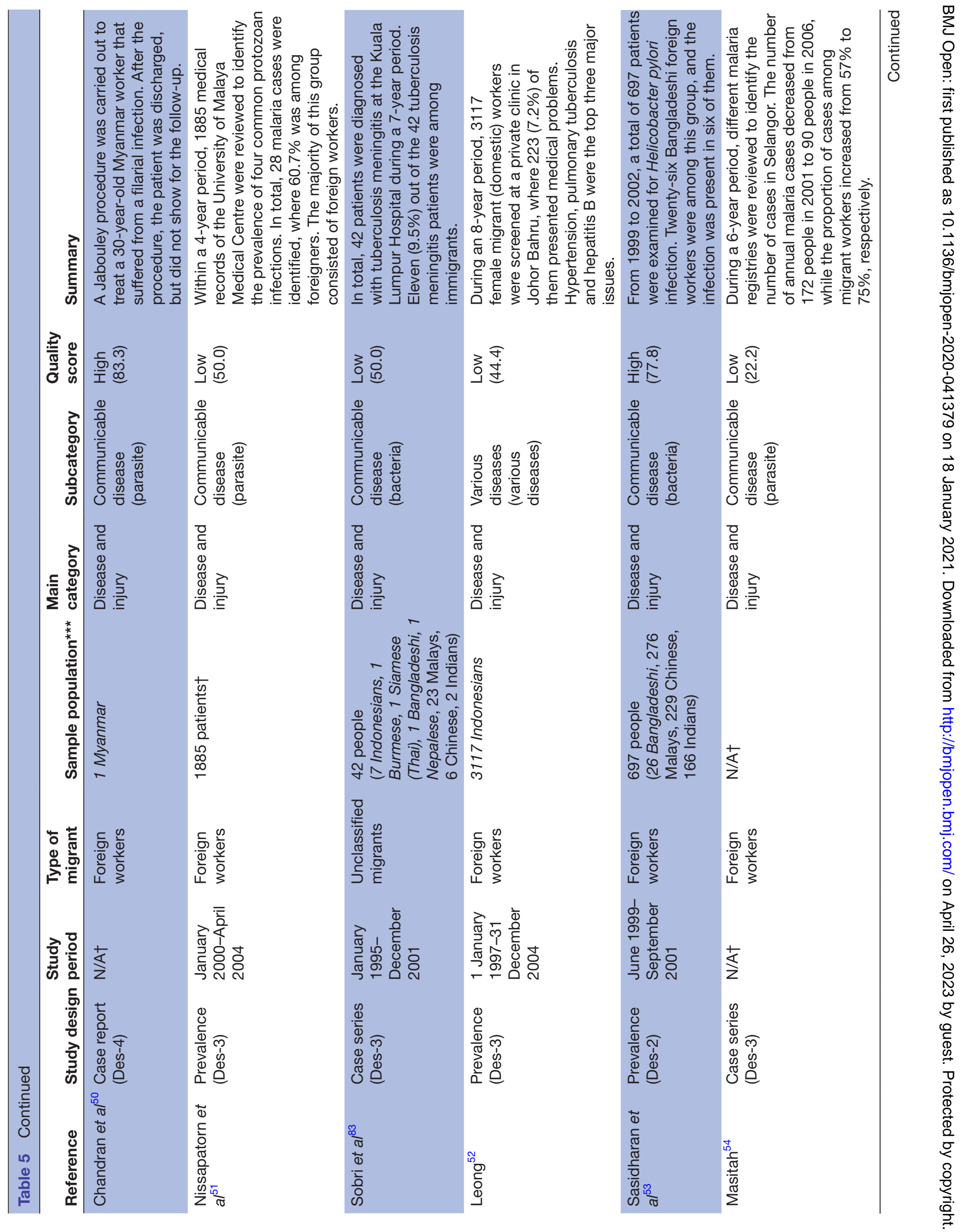




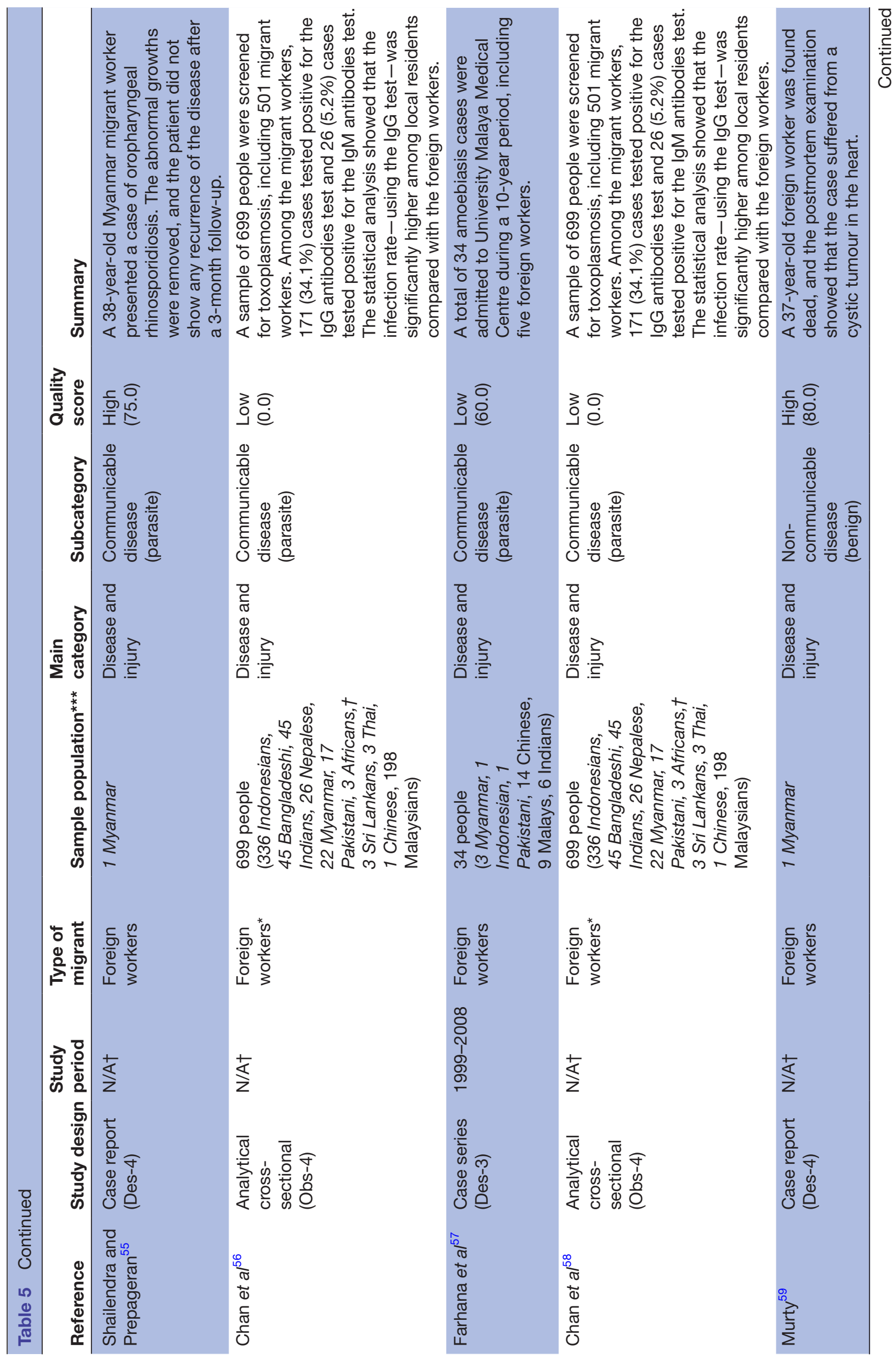




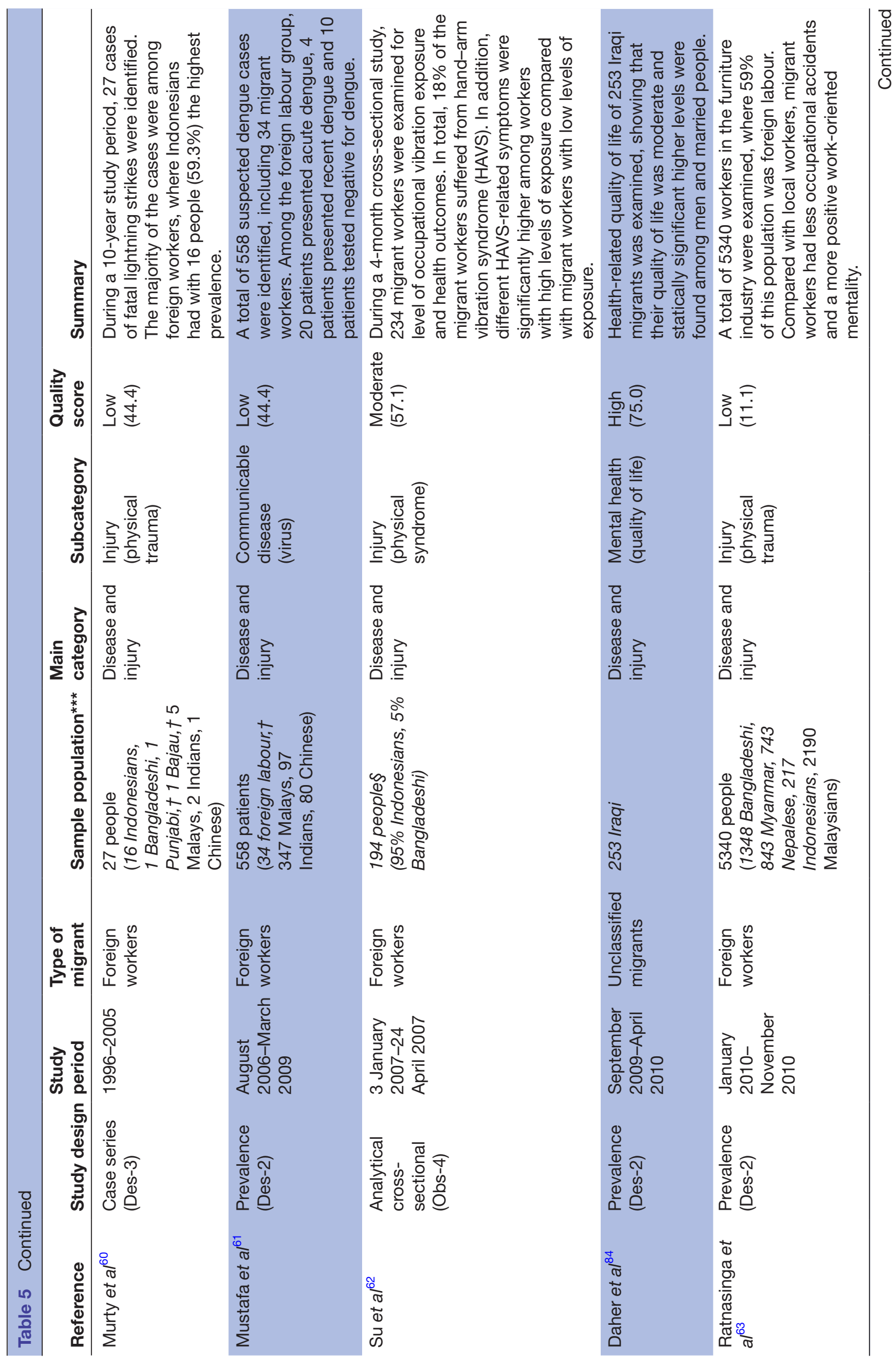




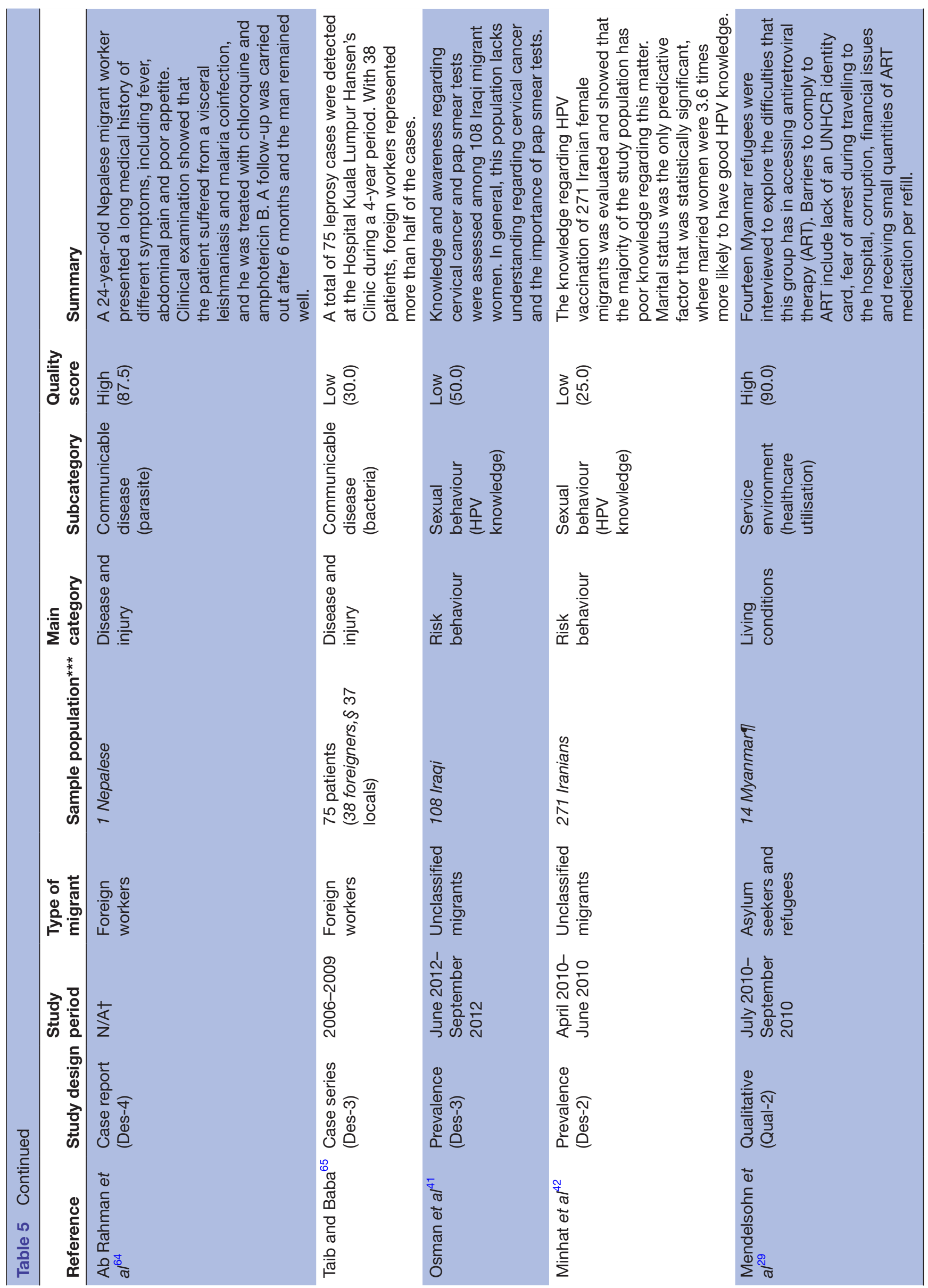




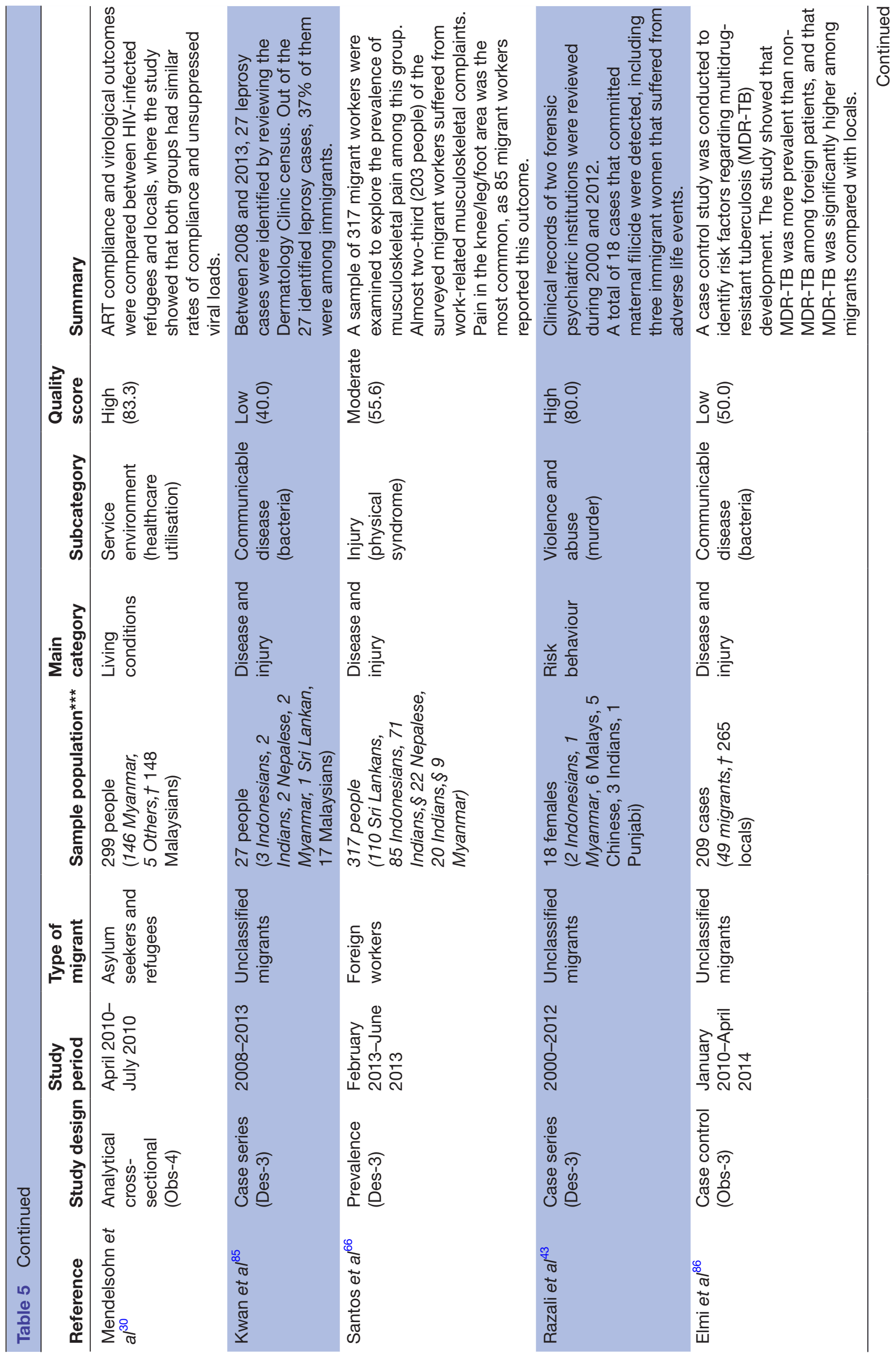




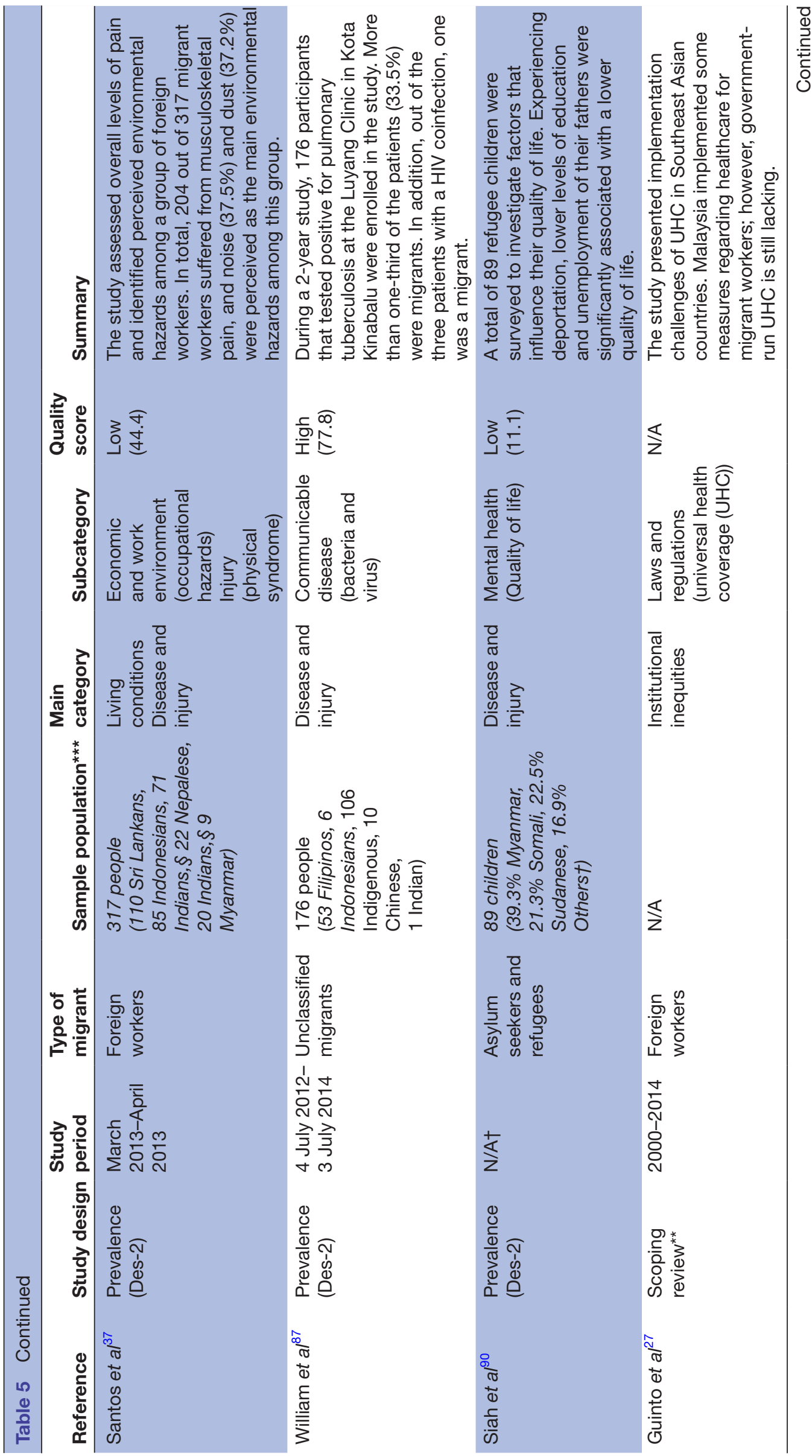




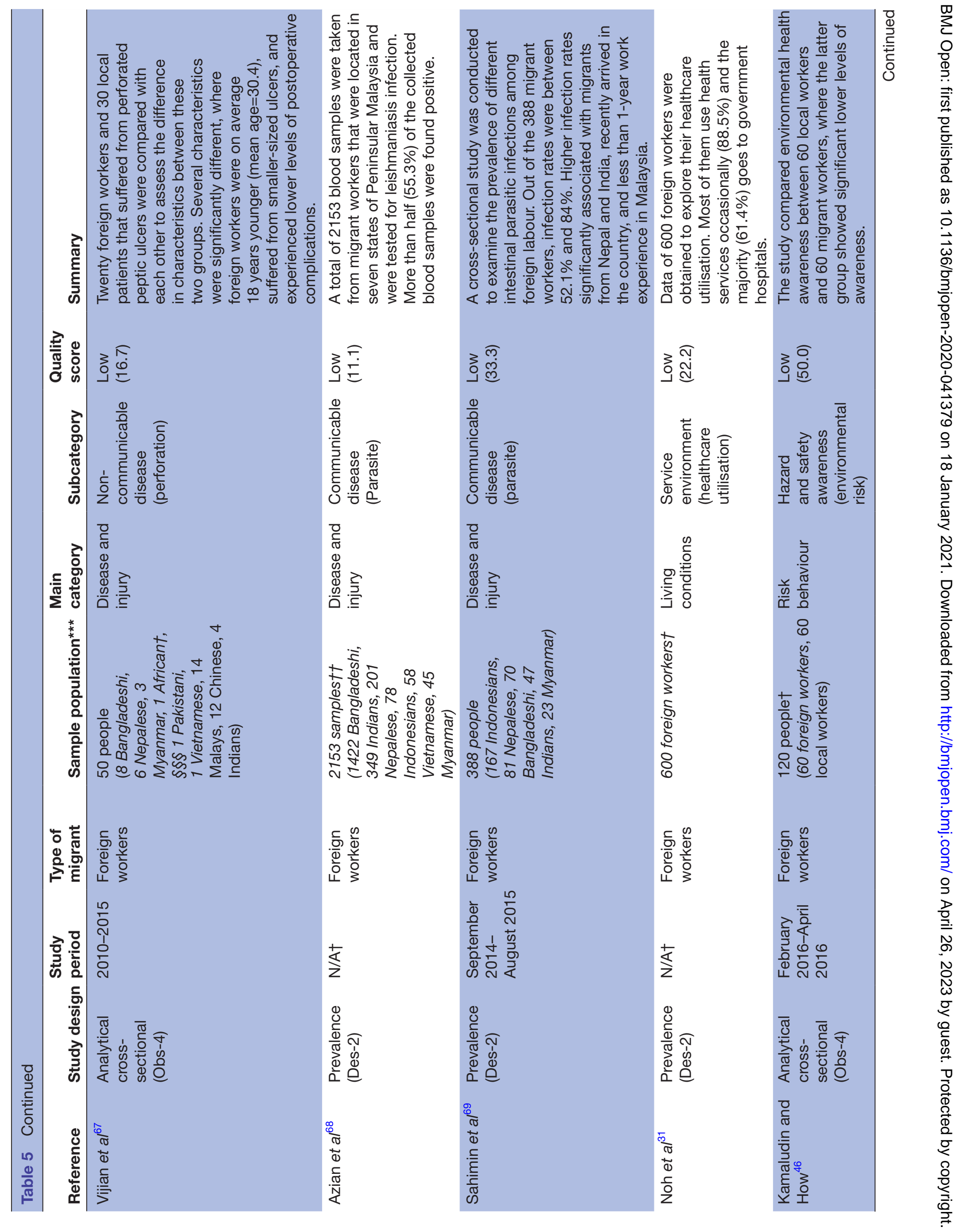




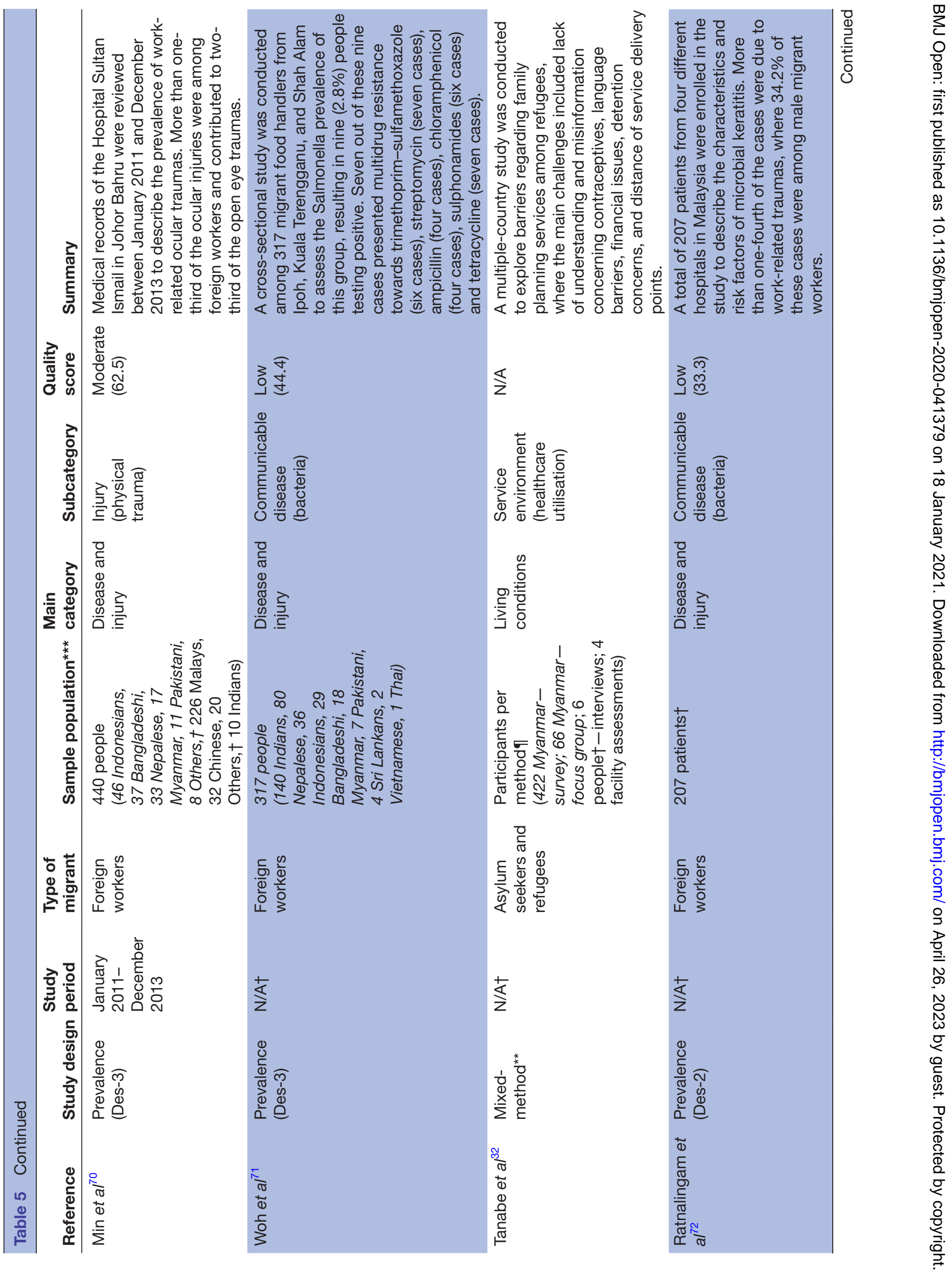




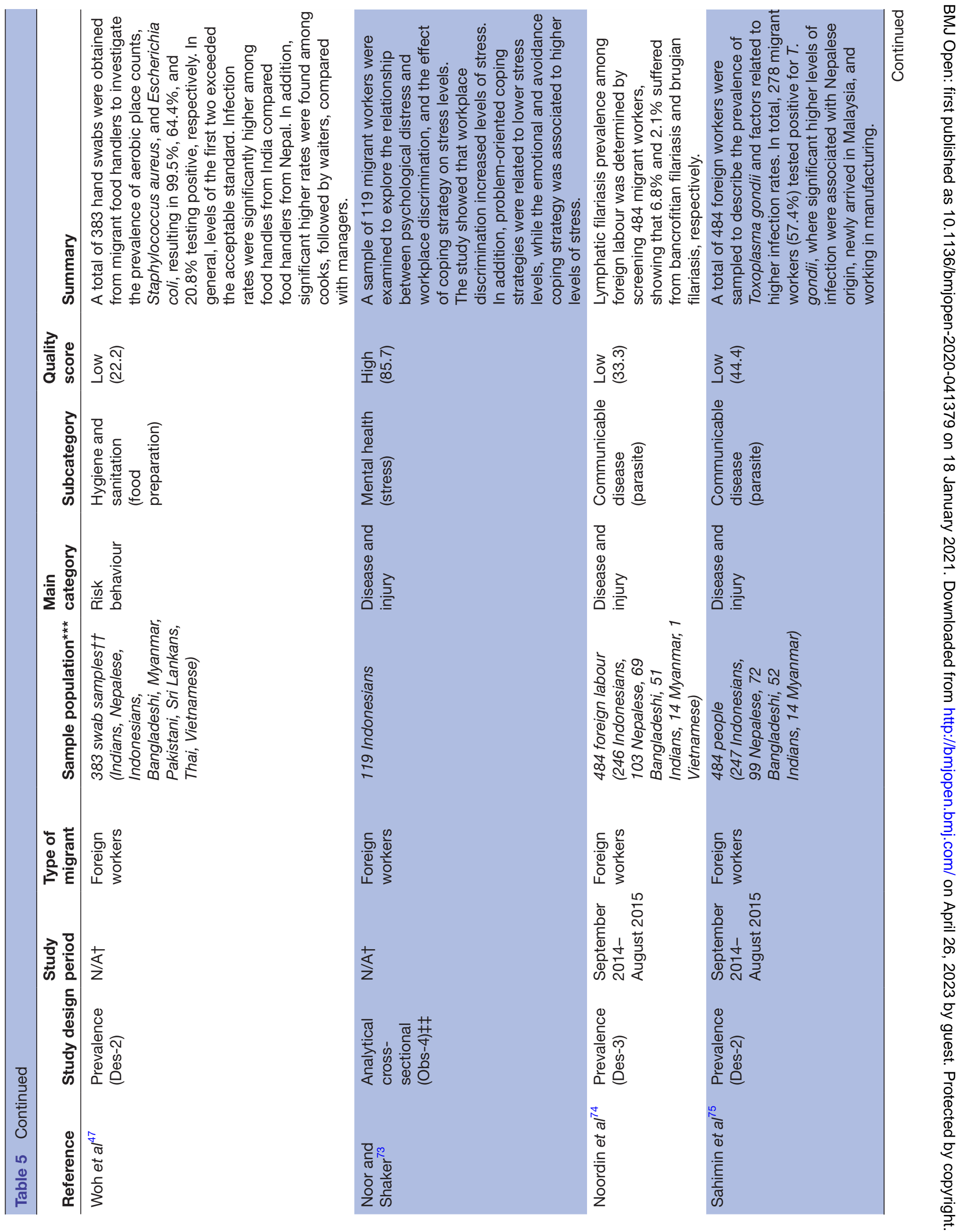




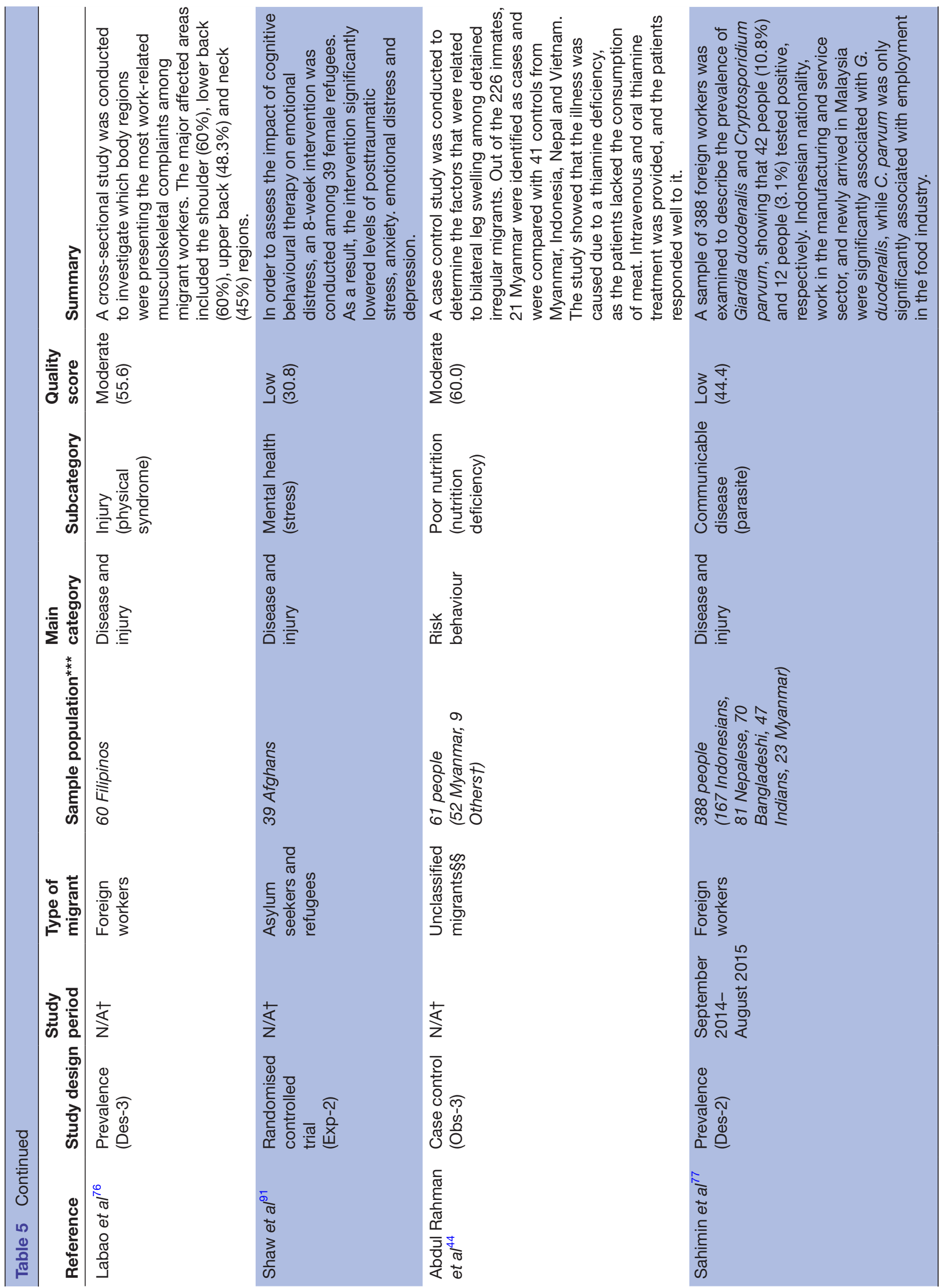




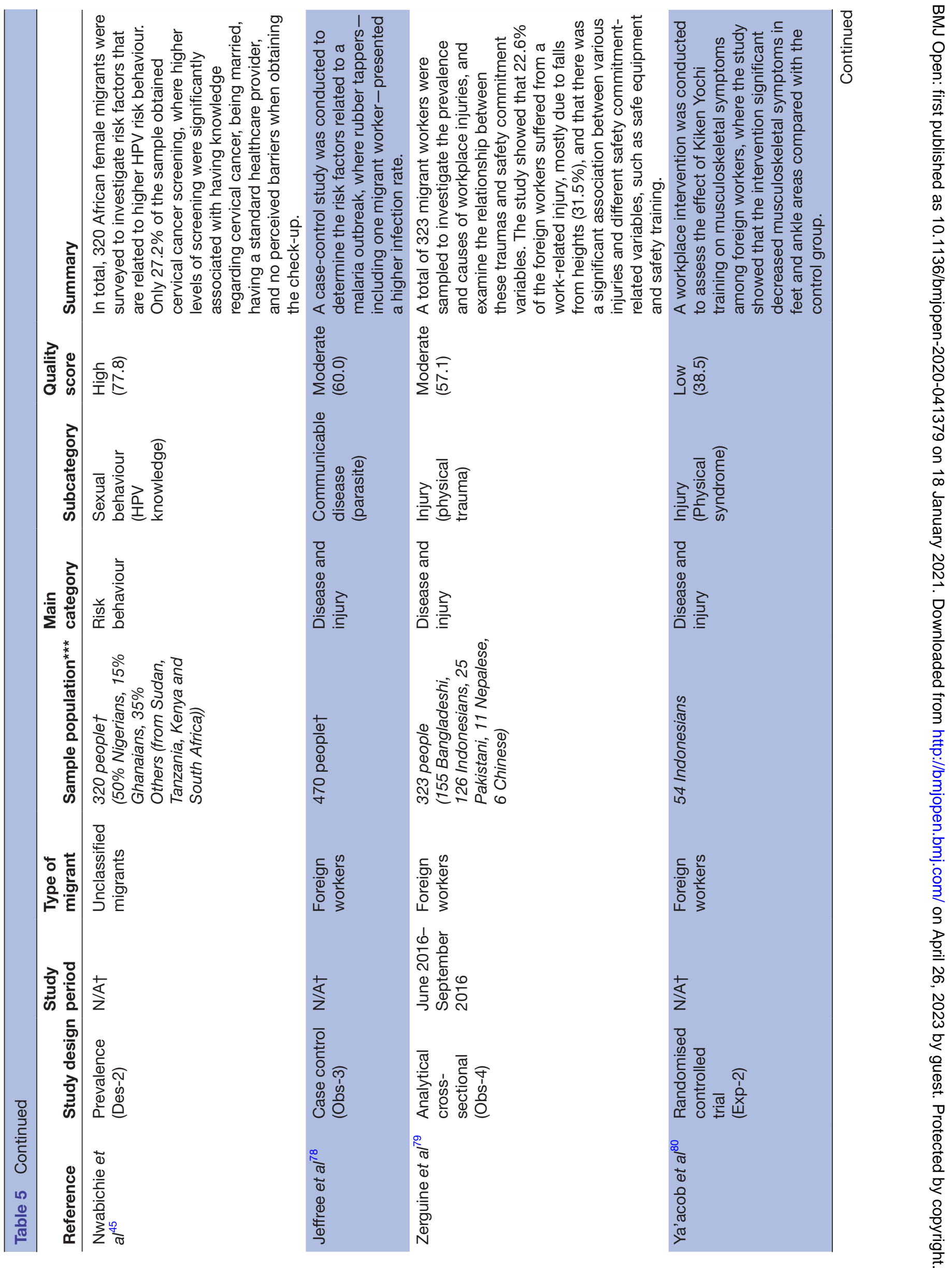




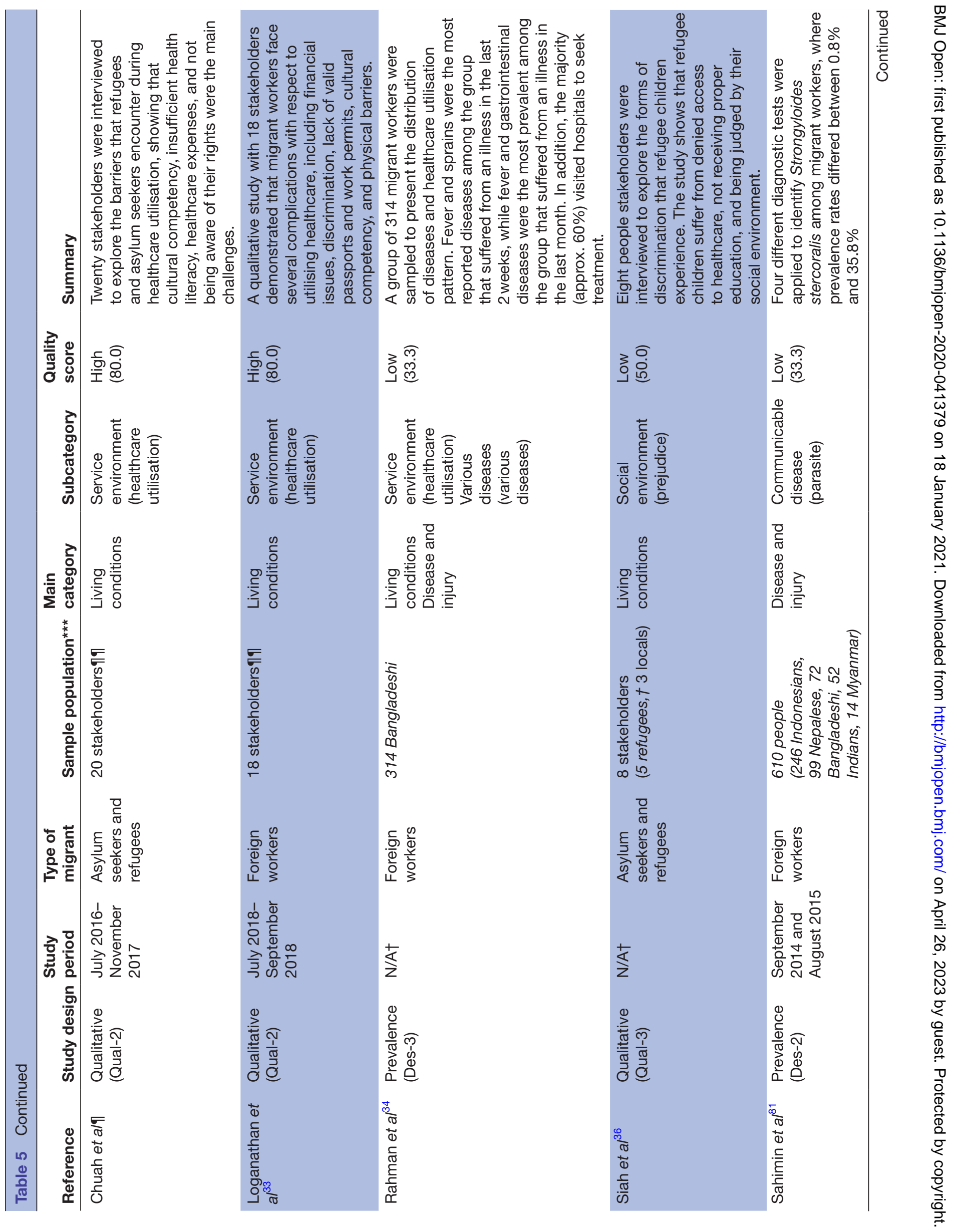



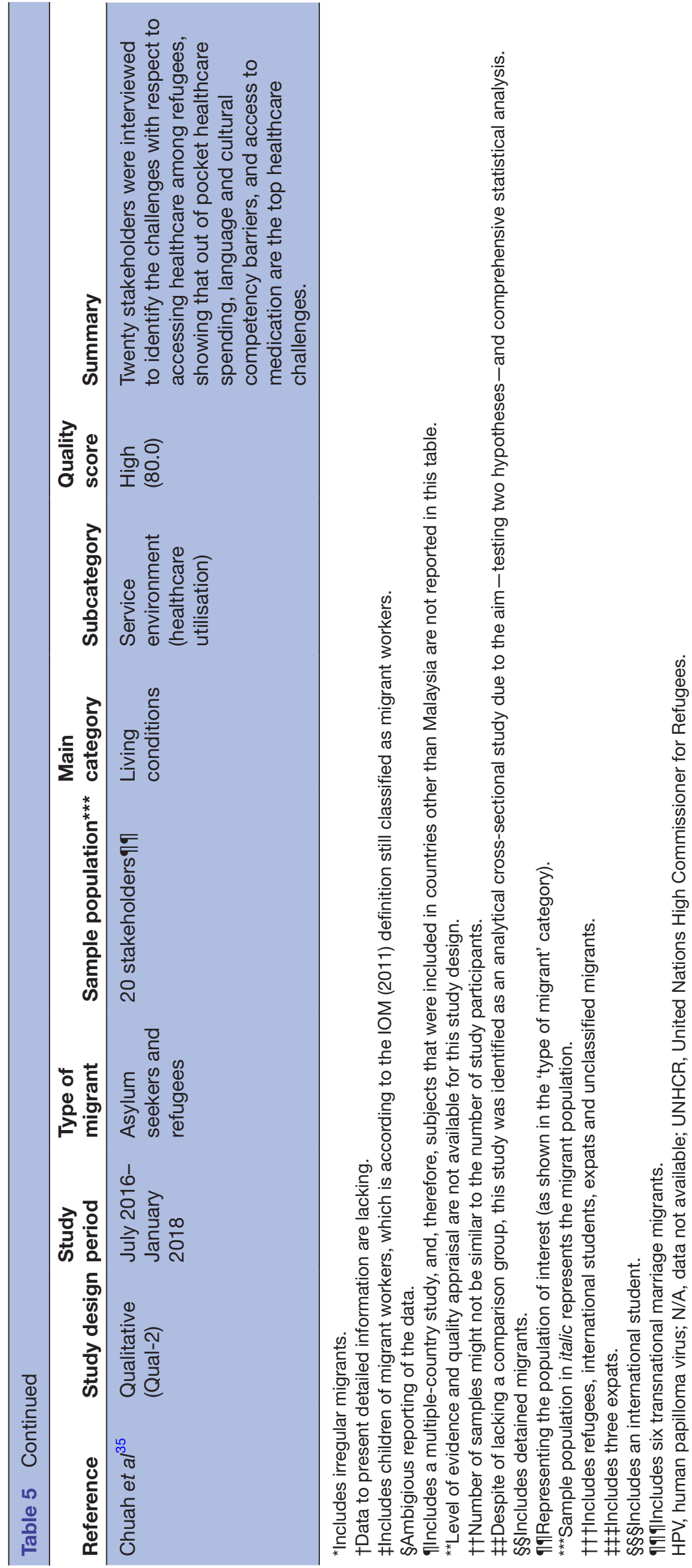
50

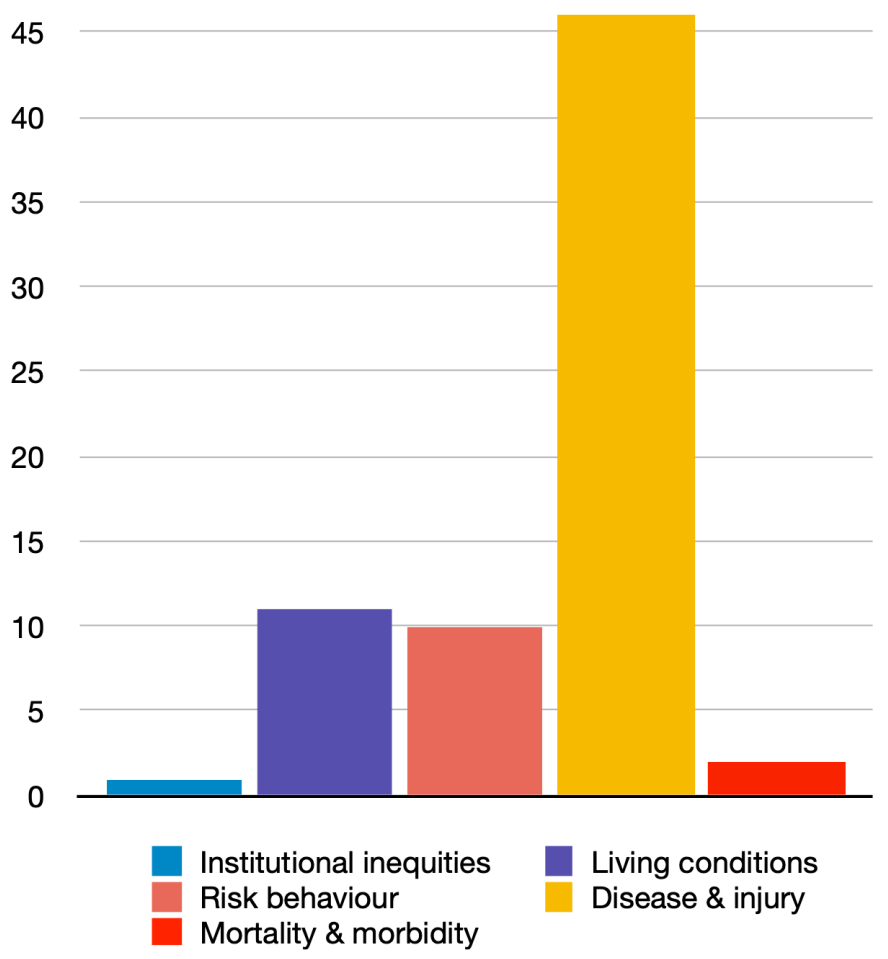

Figure 4 Number of studies disaggregated by health dimension.

summary of all included articles, including the study design and corresponding level of evidence, study period, type of migrant, sample population, main health dimension, health subdimension, quality assessment score and a short description of the study.

\section{Health dimension and type of migrant}

The literature was first assessed to understand the trends and topical coverage of research against the six dimensions of the BARHII public health framework. The first dimension, social inequities, was used to describe the population of interest and refers to the type of migrant (eg, foreign workers, asylum seekers and refugees, or unclassified migrants). The other five dimensions focused on elements that influence the health status of the population of interest, including institutional inequities, living conditions, risk behaviour, disease and injury and mortality and morbidity. These latter five categories are outlined below and include results on the types of migrants researched within these dimensions. Figures 4 and 5 present overviews of the number of studies disaggregated by health dimension and type of migrant, respectively.

\section{Institutional inequities}

One paper addressed the institutional inequities dimension ${ }^{27}$ by exploring the inclusion of migrant workers into national universal health coverage (UHC) policies in five countries of the Association of Southeast Asian Nations: Indonesia, Philippines, Malaysia, Thailand and Singapore.
50

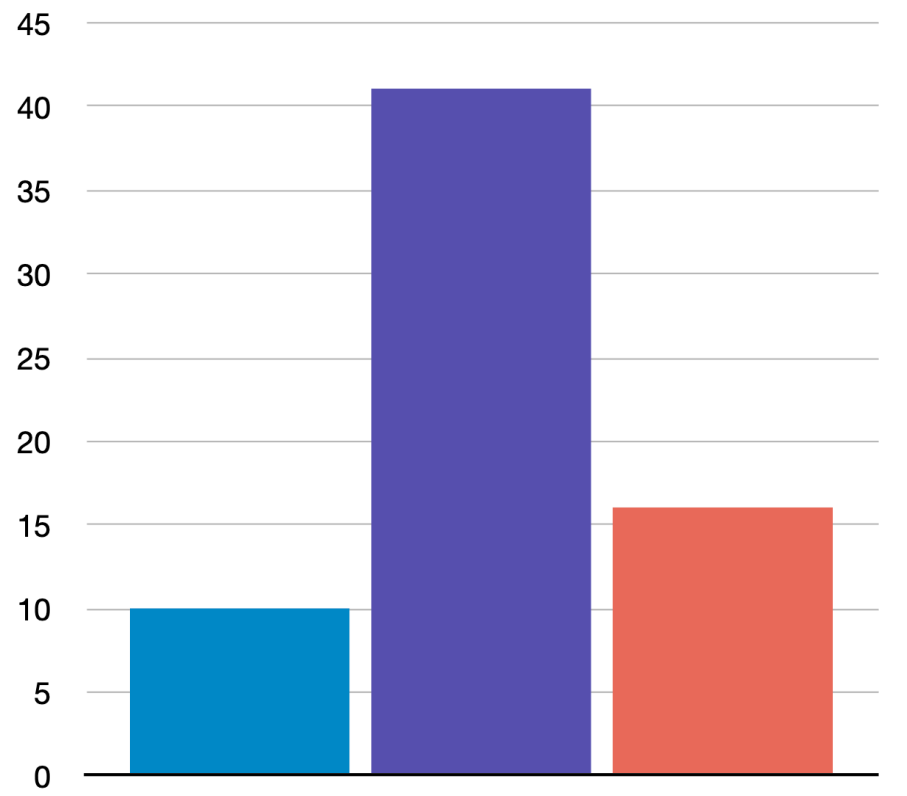

Asylum seekers \& refugees Unclassified migrants

Foreign workers

Number of studies disaggregated by type of Figure 5
migrant.

The researchers stated that Malaysia has implemented a medical insurance policy for foreign labour by obligating documented migrant workers to be enrolled in private insurance schemes, as non-citizens have no access to UHC at public facilities.

\section{Living conditions}

Eleven papers were classified under the living conditions dimension, where most articles $(n=9 / 11)$ addressed the service environment subdimension. ${ }^{8}{ }^{28-35}$ All of these papers studied the asylum seeker and refugee population, except for one article that focused on migrant workers. ${ }^{33}$ Half the studies used qualitative methods to explore barriers to healthcare utilisation and showed that language difficulties, discrimination, insufficient health literacy and cultural differences were common issues. One study focused on the social environment subdimension and showed that refugee children experienced discrimination by locals and other refugees of different ethnicities and national origins, such as stereotyping them as criminals. ${ }^{36}$ Santos $e t a l^{37}$ assessed elements related to the work environment subdimension by investigating perceived environmental hazards among foreign workers, demonstrating that noise and dust were perceived as the greatest occupational health threats.

\section{Risk behaviour}

Ten studies researched the risk behaviour dimension, with most articles $(n=8 / 10)$ conducted on general migrant populations without clear identification of which migrant categories were included in their study. ${ }^{38-45}$ Three of 
these articles focused on the sexual behaviour subdimension, exploring risk behaviour related to human papillomavirus (HPV). The studies showed that a significant number of migrant women have high HPV risk behaviour due to lack of understanding with respect to cervical cancer, the screening process, and poor knowledge concerning HPV vaccination. ${ }^{4142} 45$ Two papers, classified within the poor nutrition subdimension, showed poor health outcomes among detained migrants due to nutrition deficiencies. ${ }^{3944}$ The other articles among unclassified migrants included two studies on violence and abuse, exploring maternal filicide ${ }^{43}$ and neglecting children ${ }^{38}$; and one study on alcohol and other drugs, pertaining to inhalants' usage. ${ }^{40}$ These three studies simply showed that migrants represent a certain proportion of the identified cases. Only the study on the use of inhalants presented more cases among migrants than locals. Two final studies included foreign workers and explored the hygiene and sanitation and hazard and safety awareness subdimensions. ${ }^{46}$ Kamaludin and How $^{46}$ stated that migrant workers had significantly less knowledge regarding environmental health, such as air quality, natural hazards, sanitation and industrial hazards, compared with local workers. Woh et $a t^{t 7}$ investigated the level of hygiene among migrant food handlers and argued that personal hygiene and sanitation measures should be improved among this population.

\section{Disease and injury}

With a total of 46 studies, the disease and injury dimension presented the largest study field of interest related to the BARHII framework. Most articles $(n=36 / 46)$ studied foreign workers, ${ }^{34} 3748-81$ while only six and four articles included unclassified migrants ${ }^{82-87}$ and refugee populations, ${ }^{88-91}$ respectively. The majority $(n=27 / 46)$ of the articles studied communicable diseases, where 18 of these studies focused on parasites, ${ }^{48505154-5864686974757778818289}$ eight on bacteria, , $^{5} 6571728385-87$ and two on viruses. ${ }^{61} 87$ Most of the studies were descriptive and presented that migrants, irrespective of the defined type, represented a significant share among the study populations. Noncommunicable diseases were studied far less compared with communicable diseases and were only specifically addressed in three articles. ${ }^{59} 6788$ Scheutz et $a l^{88}$ found high numbers of different non-communicable oral complications among Vietnamese refugees, such as tooth decay and missing teeth. Kugan et a ${ }^{67}$ compared the difference in characteristics between foreign workers and Malaysian patients with perforated peptic ulcers, showing that the treated foreign labour population were younger, experienced fewer postoperative complications, and had smaller-sized ulcers compared with locals. Murty ${ }^{59}$ reported a case study, presenting a deceased migrant worker due to a cystic tumour in the heart region.

In addition to the studies that focused on single disease outcomes, two studies were conducted that presented distributions of various diseases among foreign workers, including communicable and non-communicable disorders. ${ }^{3452}$ Five studies focused on the mental health subdimension, where these studies concentrated on describing psychiatric disorders, ${ }^{49}$ determining quality of life-related risk factors, ${ }^{84} 90$ and testing the effect of different coping mechanisms and therapy sessions on the level of stress. ${ }^{73}$ N1 Nine studies explored the injury subdimension, where nearly all $(n=8 / 9)$ studies focused on work-related injuries. Most of these studies examined the prevalence of particular injuries and traumas, including fatal lightning strikes ${ }^{60}$ ocular traumas, ${ }^{70}$ and musculoskeletal pain. ${ }^{376676}$ Ratnasinga et a ${ }^{63}$ compared the number of occupational incidents between local workers and migrant workers, where foreign workers had less accidents. In addition, two papers described risk factors for work-related injuries, such as high machinerelated vibration exposure ${ }^{62}$ and low levels of the company's safety commitment (as assessed by foreign workers themselves). ${ }^{79}$ Ya'acob et $a l^{80}$ conducted an RCT to evaluate the impact of a specific workplace intervention on musculoskeletal symptoms (MMS) among foreign labour and showed that the intervention reduced MMS in the foot and ankle regions significantly compared with the control group.

\section{Mortality and morbidity}

Two papers addressed the mortality and morbidity dimension by showing incidence rates among general cohorts of migrants. Zulkifli et $a l^{28}$ conducted a study on maternal and child health in Sabah and identified that infant mortality rates were significantly higher for migrants compared with locals. Dony et $a t^{2}$ also conducted a study in Sabah and showed that at least $24 \%$ of new tuberculosis cases detected since 1990 were among migrants and that leprosy incidence rates among migrants were on average 3.7 times higher than incidence rates among Malaysians.

\section{Level of evidence and quality of the study}

In total, 65 articles were included in the quality assessment; tables 6 and 7 show the mean quality scores of the papers disaggregated by BARHII dimension and level of evidence, respectively. Two articles-representing a scoping review ${ }^{27}$ and mixed-method design ${ }^{32}$-were excluded from this assessment, as the JBI toolkit does not accommodate these study designs. The quality assessment scores can be found in online supplemental file 3 . In addition, figure 6 shows an overview of the number of studies disaggregated by research design.

In general, the quality of the evidence base on migrant health in Malaysia is low (49.2\%) and consists mostly of level 3 evidence papers $(n=27 / 65)$. Level 2 evidence represents $38.5 \%$ of the evidence base $(n=25 / 65)$, followed by level 4 evidence papers $(n=13 / 65)$. No level 1 evidence studies (systematic reviews or meta-analyses) were identified. The majority of the papers $(n=41 / 65)$ focused on foreign workers; however, studies that included asylum seekers and refugees have the highest mean quality $(58.4 \%)$. Furthermore, only four out of five BARHII health dimensions were included in the 


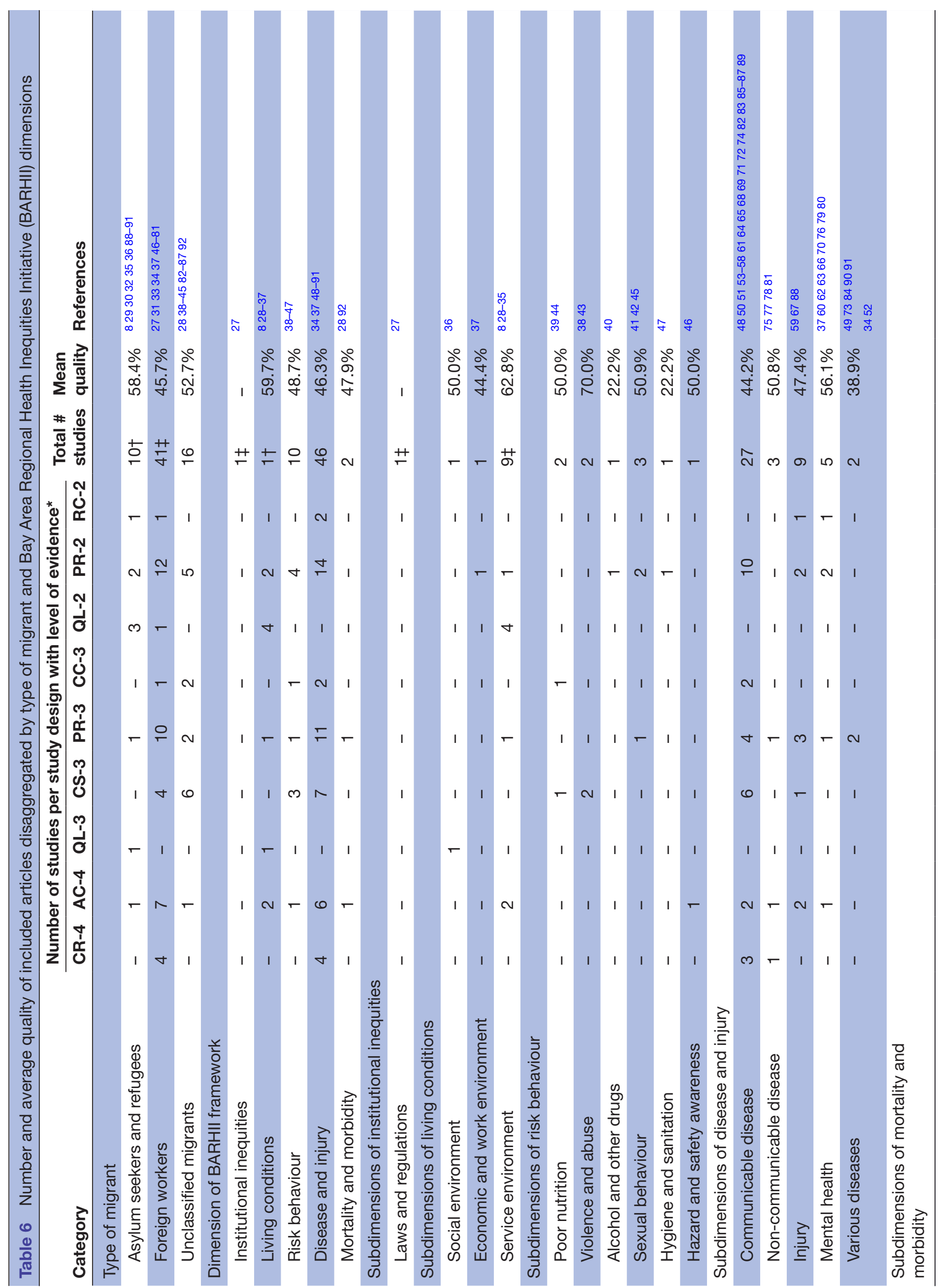


quality assessment. The living conditions dimension has the highest average score $(59.7 \%)$, followed by the risk behaviour dimension (48.7\%), mortality and morbidity dimension $(47.9 \%)$, and the disease and injury dimension $(46.3 \%)$. Moreover, the descriptive research category represents the majority $(70.8 \%)$ of the evidence base with a mean quality of $47.7 \%$. The qualitative research category has the highest mean quality and is the only research category with a high-quality score $(76 \%)$.

\section{Associations between different variables}

Figure 7 presents the results of the MCA, showing different associations between four dimensions: (1) type of study design; (2) quality of the study; (3) type of migrant; and (4) main health dimension. $\chi^{2}$ test results were used to assess whether categorical variables were independent.

High-quality studies tend to include refugees and asylum seekers $\left(\chi^{2}=17.005, \mathrm{df}=4, \mathrm{p}=0.001928\right)$, focus on living conditions $\left(\chi^{2}=131.94, \mathrm{df}=6, \mathrm{p}<0.001\right)$, and have a qualitative research design $\left(\chi^{2}=656.35, \mathrm{df}=12, \mathrm{p}<0.001\right)$. Moreover, studies that included foreign workers tend to focus on diseases and injuries $\left(\chi^{2}=374.52, \mathrm{df}=6, \mathrm{p}<0.001\right)$ and contain a case report study design $\left(\chi^{2}=576.87, \mathrm{df}=12\right.$, $\mathrm{p}<0.001)$. Furthermore, research that included the unclassified migrant population tend to study the risk behaviour, and mortality and morbidity dimensions $\left(\chi^{2}=374.52\right.$, $\mathrm{df}=6, \mathrm{p}<0.001)$. Lastly, prevalence studies, and, to a lesser extent, analytical cross-sectional studies, tend to have a low-quality score $\left(\chi^{2}=656.35, \mathrm{df}=12, \mathrm{p}<0.001\right)$.

\section{DISCUSSION \\ Key findings}

This study mapped the existing academic literature on migrant health in Malaysia and assessed the quality and level of evidence of these scientific studies. The majority of these studies focus on the 'disease and injury' dimension, especially infectious diseases, and includes mostly foreign workers. Two health dimensions (institutional inequality, and morbidity and mortality) as well as various subdimensions of each health dimension are lacking substantial research. In addition, only a few papers include the asylum seeker and refugee population, and a vast amount do not provide any details to classify the type of migrant. The average quality of the papers was low, yet quality differed significantly among the studies. High-quality studies were mostly qualitative designs that included refugees and focused on living conditions, while prevalence and analytical cross-sectional studies were mostly low quality. In terms of research trends, no specific changes in type of migrant, health dimension or quality of the study have been observed over the last six decades. However, it should be noted that qualitative research made its entry in the early 2010s and made up a vast amount of the papers published in recent years. Future research priorities based on the existing evidence and identified gaps are summarised in box 1 . 
Table 7 Number and average quality of included articles disaggregated by research design category

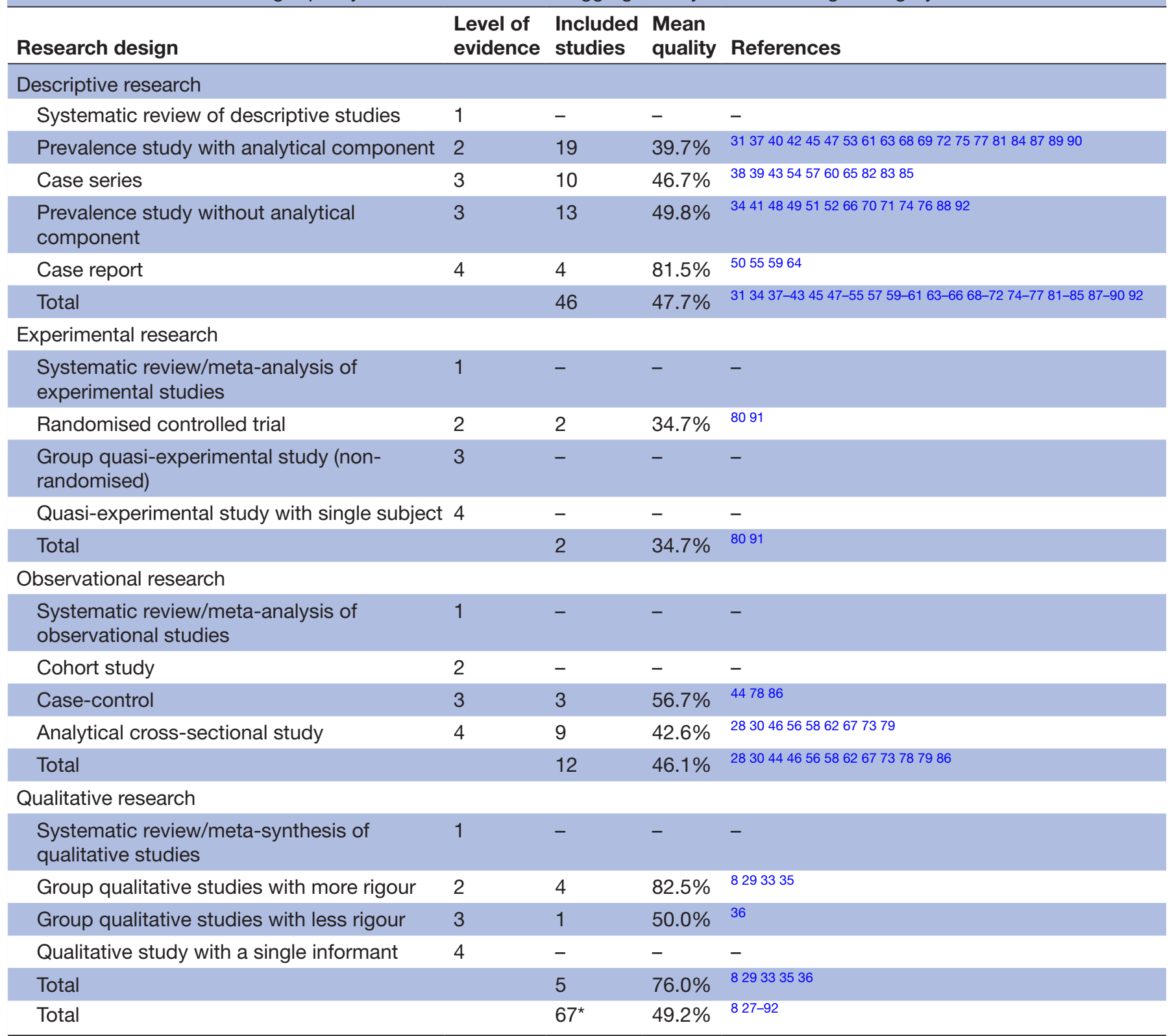

*Includes a mixed-method design and a scoping review, which were both not assessed for the level of evidence nor quality appraisal.

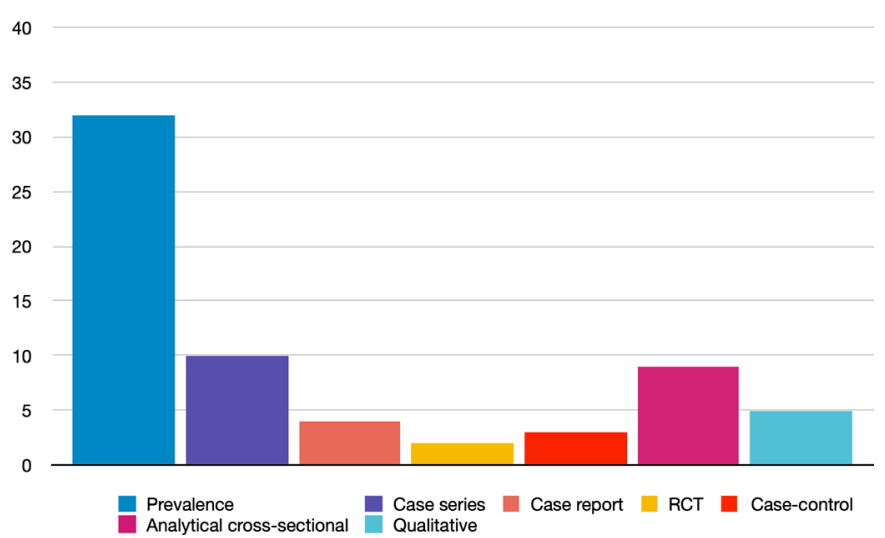

Figure 6 Number of studies disaggregated by research design.
Among the five BARHII health dimensions, institutional inequities, and mortality and morbidity were the least represented. Yet, studies concerning the influence of governance on migrant health are of utmost importance, as overarching governance can affect health outcomes of the other BARHII dimensions. ${ }^{93}{ }^{94}$ Similarly, epidemiological research on mortality and morbidity rates is necessary for population health statistics, to identify disease patterns, document changes over time and inform plans of action to tackle these health issues. ${ }^{95}$ Further research should focus on migrant health governance, as well as epidemiological research on morbidity and mortality among both migrants and non-migrants, to better understand the effects of policies on migrant health, which is particularly relevant in low-income and 


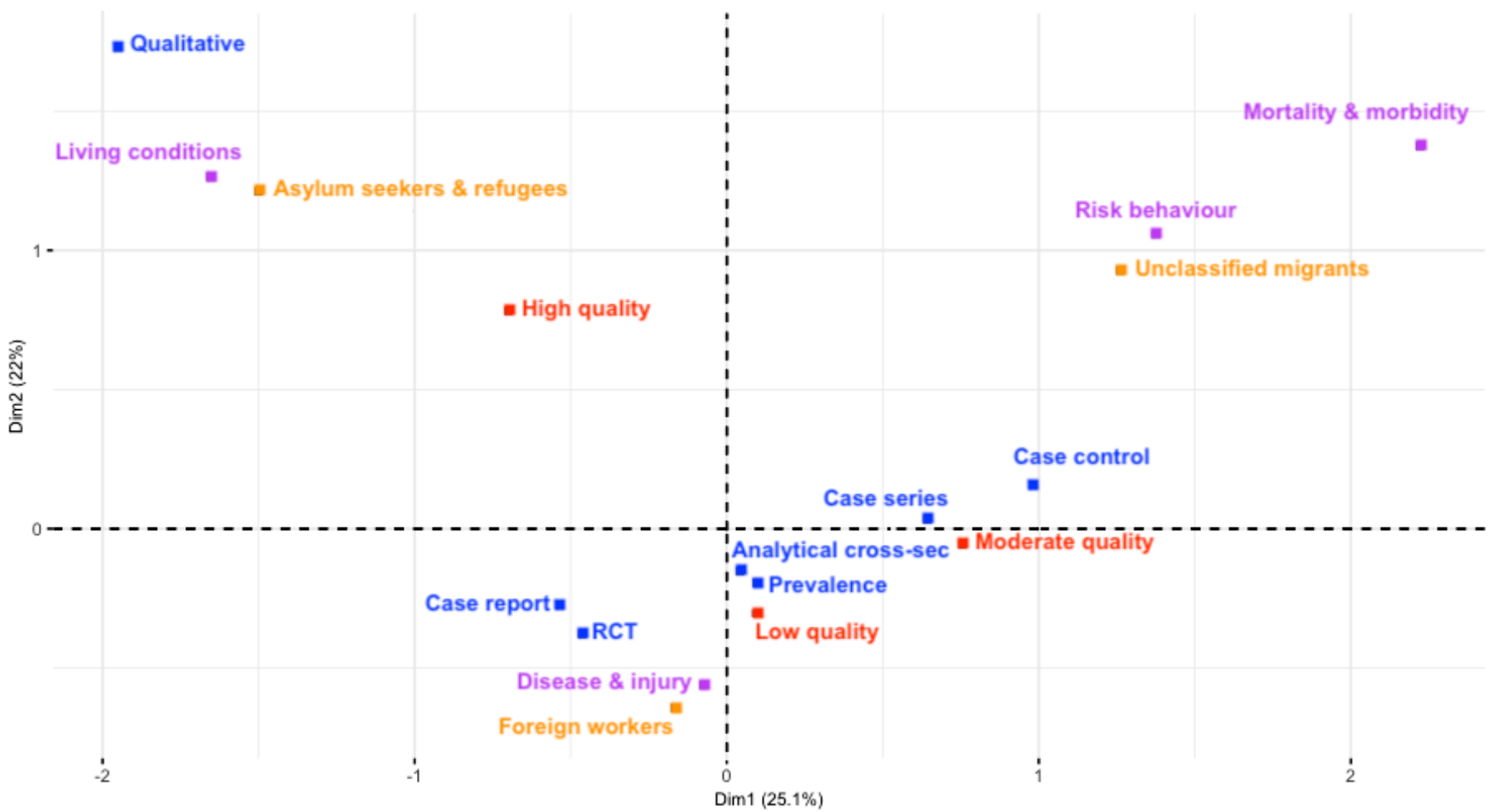

Figure 7 Results of the multiple-correspondence analysis.

Box 1 Main recommendations to improve future research on migrant health

\section{Recommendation}

- Improve the description of the target migrant population by including information regarding the type of migrant (eg, foreign worker, refugee), visa status (eg, regular, irregular), country of origin, socioeconomic variables (eg, level of education, income), mode of transport during migration journey (eg, boat, car) and the existence of forced entry (eg, human trafficking, forced marriage).

- Create associations between different stages of migration (predeparture, travel, destination, interception and return phase) and health outcomes.

- More research output concerning governance and institutional inequities and mortality and morbidity, and, consequently, conduct a time series analysis between these two dimensions to identify and possible relationships.

- More research output regarding non-communicable diseases, especially on the main causes of death in Malaysia; cardiovascular diseases, chronic respiratory diseases and diabetes.

- More research output concerning several subdimension of risk behaviour, especially on smoking, physical inactivity, and alcohol abuse.

- Evaluate the impact of health and non-health policies on migrant health.

- Explore living conditions regarding the physical environment, such as housing and environmental conditions, and the impact on migrant health outcomes.

- Promotion of guidelines on study conduct and reporting among researchers. middle-income countries where the evidence gap is so acute. ${ }^{96}$ Furthermore, a recent systematic review on the effects of non-health-targeted policies on migrant health in high-income countries showed that non-health policies (eg, restrictive immigration policies) were associated with poor health outcomes. ${ }^{97}$ It is therefore important that policies in other sectors (potentially including, eg, immigration, labour, education) are also assessed for their potential consequences for migrant health.

Living conditions were represented in 11 studies and focused mainly $(n=9 / 11)$ on the service environment by addressing the healthcare setting. However, there is scarce information on the social and economic environments that different categories of migrants must navigate and no data on the physical environment at all. Research conducted in other countries demonstrates the importance of these three subdimensions on migrant health. ${ }^{98-100}$ Shao et a ${ }^{98}$ argued that inequalities regarding the level of income (economic environment) influenced health outcomes among internal migrant workers in China. He and Wong ${ }^{99}$ stated that poor mental health among female migrant workers in China was related to gender-specific stressors (social environment). Al-Khatib et $a l^{100}$ demonstrated that poor housing conditions (physical environment) in a refugee camp were directly associated with various upper respiratory tract diseases. These studies underscore the importance of different environments on migrant health, motivating a focus of future research on the health impact of living conditions other than healthcare utilisation. 
Ten studies were conducted on risk behaviour with different subdimensions, from hygiene and sanitation to violent and abusive behaviour. However, all of these subdimensions were under-researched, as only limited elements of each subdimension were discussed. For instance, three studies focused on sexual behaviour by addressing HPV knowledge. ${ }^{41} 42{ }^{45}$ Yet, no attention was given to other sexual behaviour-related topics, such as condom use, HIV knowledge and birth control. Although these studies have been conducted in Malaysia, this research is lacking in the migration context. ${ }^{101-103}$ Therefore, future research should focus on broader aspects of each subdimension, as demonstrated in research elsewhere. For example, Renzaho and Burns ${ }^{104}$ addressed the poor nutrition subdimension by showing that dietary patterns among African migrants changed negatively after arriving in Australia due to the increased intake of fast food and processed food. Ganle et al ${ }^{105}$ concentrated on the sexual risk behaviour subdimension and stated that $71 \%$ of the sampled refugees in Ghana had transactional sex, and only $12 \%$ used contraceptives. Bosdriesz et al ${ }^{106}$ compared smoking between migrants and non-migrants in the USA and showed that migrants smoked less than US citizens. As a significant number of migrants in Malaysia come from Indonesia, a population that smokes almost twice as much as Malaysians, smoking behaviour among this migrant group may differ from locals. ${ }^{107}$ Therefore, future research should further explore the differences in other risk behaviours, such as smoking, between Malaysians and migrants in Malaysia.

Disease and injury was the most researched dimension, representing more than two-thirds of the evidence base on migrant health in Malaysia. Despite the strong representation, over half the research papers concentrated on communicable diseases, while only a few examined non-communicable diseases, consistent with global research output on international migrant workers. ${ }^{108}$ As the $\mathrm{WHO}^{109}$ states that approximately $74 \%$ of all deaths in Malaysia are attributable to non-communicable disease, in particular cardiovascular disease, chronic respiratory disease and diabetes, there is a need to expand research on non-communicable disease trends and outcomes among the migrant population in Malaysia.

We found that the majority of studies involved foreign workers $(n=41 / 67)$, and only 10 studies examined asylum seekers and refugees as the primary population of interest. Our findings, therefore, offer useful synthesis on migrant worker's health specifically, which is lacking relative to studies on asylum seekers and refugees in global migration health research. ${ }^{13}$ Furthermore, 11 studies did not specify the included migrant population. This issue could have occurred due to missing information on the type of migrant in the dataset that the researchers used for their studies. For example, the Ministry of Health $(\mathrm{MOH})$ will not report anything more detailed than 'non-Malaysian,' as no further information on non-citizens are collected during patient registration at $\mathrm{MOH}$ facilities. Ideally, all research on migrants should clearly specify the type of migrants being studied and not omit crucial details, such as gender, visa status and country of origin. Also, human trafficking could significantly affect a person's health and vulnerability, yet, there is very little known about the health issues experienced by trafficked persons in Malaysia. ${ }^{110}$ While the vulnerabilities experienced by trafficked persons intersect with other migration-related vulnerabilities like gender, ethnicity or documentation status, victims of human trafficking should be categorised separately, to reflect their own unique status and vulnerability. The travel routes or modes of transportation used by migrants to come to Malaysia may influence migrant health in different ways a well, as different routes or modes of transportation may be linked with specific hazards. Related to this issue is the lack of evidence on migrant health with specific stages of migration, including predeparture, travel, destination interception and return, where health outcomes might differ between these stages. ${ }^{111}$

Lastly, this scoping review revealed that the average quality of studies on migrant health in Malaysia is poor $(49.2 \%)$ and that most of these studies have level 3 $(n=27 / 65)$ or level $2(n=25 / 65)$ evidence. Only qualitative studies with more rigour (level 2 evidence) and those that focus on living conditions and include the refugee and asylum seeker populations, tend to have a high-quality score. Therefore, there is a clear need to conduct research that will provide strong evidence to support practices and policies that will positively impact migrant health. Creating standard research designspecific guidelines, if not existing already, and, subsequently, promoting these materials among academics and research institutions, could increase the quality of future research work. Furthermore, researchers should follow study design specific reporting guidelines, to ensure that all relevant information is captured in publications for further evidence synthesis, such as this review.

\section{Limitations}

This study is the first systematic literature synthesis and scoping review on migrant health in Malaysia and presents a comprehensive overview of all identified peerreviewed articles that met the inclusion criteria. Specific recommendations based on this research are provided to improve the evidence base on migrant health in Malaysia. Furthermore, we used a self-developed decision tree and modified JBI checklists to help identify the type of study design and corresponding level of evidence of the included studies. We found this evidence assessment framework to be useful for the quality assessment of migrant health-related studies, and it might be useful for other research fields as well. Yet, our review has several limitations. As this paper focuses exclusively on vulnerable migrants within the non-citizen population in Malaysia, we excluded other non-citizen groups, such as expatriates and international students, based on the assumption that these groups are less vulnerable (eg, expatriates in Malaysia have more privileges in terms of 
recognition regarding their roles in society, receive better financial compensation and tend to have access to many other benefits compared with foreign workers). However, we acknowledge that other non-citizen groups may face challenges in obtaining proper healthcare in Malaysia as well, such as issues related to cultural competency among foreign students and retirees. ${ }^{112} 113$ In addition, papers including non-citizens without further description were excluded, although these studies may have included the vulnerable migrant population.

Only academic peer-reviewed studies were included, thus excluding grey literature, editorials and opinion papers. Also, only English language articles were included, resulting in the exclusion of one identified paper in Bahasa Malaysia (the Malay language) ${ }^{114}$ Aggravating the issue, other Malaysian articles might not have been identified due to the lack of Malaysian keywords in the search strategy. As a result, much relevant information that could potentially be used to inform both policies and practice, as well as to make this review more comprehensive, may have been excluded from this review.

Inter-rater reliability was limited to a $20 \%$ sample of the records in the first (abstract and title) screening stage, and no data extraction nor quality assessment was verified by a second reviewer due to time and resource constraints. Yet, we anticipate low selection bias as the health dimensions in the BARHII framework present clear distinctions between each other, and most of the included papers used objective indictors. For example, when a paper was measuring the knowledge and awareness regarding the pap smear test among female migrants, it would be classified as a 'risk behaviour' study. Furthermore, we believe that the development of the decision tree and additional objective criteria for the JBI tools—an example was given earlier in table 4-reduced the subjectivity of this study, and, hence, increases the reliability. Yet, future research is needed to validate both the decision tree and modified JBI toolkit.

Besides the BARHII framework, various conceptual public health models are available, and these models may include different (sub)dimensions. For instance, the WHO Commission on Social Determinants of Health framework includes material circumstances, such as food availability, whereas this dimension is not included in the BARHII framework. ${ }^{115}$ Similarly, critical appraisal tools other than the JBI toolkit are available, which could address different points to determine the quality of the study. Therefore, it would be helpful to assess other public health models and critical appraisal tools to see if they include additional elements (eg, food availability) that would be beneficial for future studies.

Likewise, a decision tree was developed by using the characteristics of the used definitions of different research designs as well as the specific traits of Tomlin and Borgetto's ${ }^{24}$ level of evidence model. Using other definitions and level of evidence models could result in a different level of evidence categorisation. However, we believe this review makes a strong methodological contribution by combining study designs and level of evidence in a unified decision tree, which can be used by researchers conducting systematic or scoping reviews where accurate classification of the study design and associated evidence level, is important.

In order to conduct the MCA, the dataset could only include one unit per dimension for each paper. As some studies included multiple BARHII dimensions, only the most prominent dimension was included in the analysis. As a result, the analysis may suffer from some selection bias and present slightly different outcomes compared with an analysis that includes the other BARHII dimensions.

Lastly, no adjustments were made for outliers in the quality assessment. Therefore, some papers with extremely high or low scores could have influenced specific dimensions and might not reflect the quality of those dimensions perfectly.

\section{CONCLUSION}

Migrant health remains an issue in Malaysia, yet, the quality of the evidence needed to inform policies is currently lacking. Research-specific reporting guidelines should be followed to improve the credibility and quality of the evidence base. Furthermore, future research should focus more on evidence gaps in the mortality and morbidity, and institutional inequities dimensions, and certain subdimensions, such as non-communicable diseases, housing conditions and physical inactivity, to provide a comprehensive picture of migrant health in Malaysia. Apart from demonstrating the research gaps, this paper also makes methodological contributions to migrant health research by providing a modified JBI toolkit and a decision tree that identifies the type of study design and corresponding level of evidence, both of which can be used in other research fields as well.

\section{Author affiliations}

${ }^{1}$ Maastricht Graduate School of Governance, Maastricht University, Maastricht, The Netherlands

${ }^{2}$ United Nations University-Maastricht Economic and Social Research Institute on Innovation and Technology, Maastricht, The Netherlands

${ }^{3}$ United Nations University — International Institute for Global Health, Kuala Lumpur, Malaysia

${ }^{4}$ Centre for Epidemiology and Evidence-based Practice, Department of Social and Preventive Medicine, University of Malaya, Kuala Lumpur, Malaysia

${ }^{5}$ Gender Violence \& Health Centre, London School of Hygiene and Tropical Medicine, London, UK

Acknowledgements The authors would like to thank Andrew Seko for granting them permission on behalf of the Bay Area Regional Health Inequities Initiative (BARHII) for the use of their public health framework in this scoping review. They would also like to thank Norhayati Binti Yahya for providing them with the definition for non-citizens on behalf of the Department of Statistics Malaysia (DOSM).

Furthermore, they would like to thank the editor and four independent reviewers for their helpful feedback. Lastly, they would like to thank the United Nations University - International Institute for Global Health for its continuous support throughout this project.

Contributors AWdS, NSP, MV and ZXC created the study protocol. AWdS and ZXC conducted abstract and full-text screening and NSP solved undisputed conflicts. AWdS extracted the data, drafted the decision tree and modified the JBI tools, and NSP, MV, ZXC and CAL provided feedback during these processes. CAL and AWdS 
conducted the data analysis. AWdS drafted the initial version of the manuscript and AWdS, NSP, MV, CAL, TL and ZXC critically revised and approved the final version.

Funding The authors have not declared a specific grant for this research from any funding agency in the public, commercial or not-for-profit sectors.

Competing interests All authors have completed the Unified Competing Interest form (available on request from the corresponding author) and declare: no support from any organisation for the submitted work; no financial relationships with any organisations that might have an interest in the submitted work in the previous three years; no other relationships or activities that could appear to have influenced the submitted work.

Patient consent for publication Not required.

Provenance and peer review Not commissioned; externally peer reviewed.

Data availability statement Data are available upon reasonable request. All data relevant to the study are included in the article or uploaded as supplementary information. The prereview protocol and modified JBI checklists can be accessed on request from the first author.

Supplemental material This content has been supplied by the author(s). It has not been vetted by BMJ Publishing Group Limited (BMJ) and may not have been peer-reviewed. Any opinions or recommendations discussed are solely those of the author(s) and are not endorsed by BMJ. BMJ disclaims all liability and responsibility arising from any reliance placed on the content. Where the content includes any translated material, BMJ does not warrant the accuracy and reliability of the translations (including but not limited to local regulations, clinical guidelines, terminology, drug names and drug dosages), and is not responsible for any error and/or omissions arising from translation and adaptation or otherwise.

Open access This is an open access article distributed in accordance with the Creative Commons Attribution Non Commercial (CC BY-NC 4.0) license, which permits others to distribute, remix, adapt, build upon this work non-commercially, and license their derivative works on different terms, provided the original work is properly cited, appropriate credit is given, any changes made indicated, and the use is non-commercial. See: http://creativecommons.org/licenses/by-nc/4.0/.

\section{ORCID iDs}

Allard Willem de Smalen http://orcid.org/0000-0002-9633-1976

Tharani Loganathan http://orcid.org/0000-0001-6690-000X

Nicola S Pocock http://orcid.org/0000-0002-2083-4171

\section{REFERENCES}

1 International Organization for Migration. World migration report 2020. Geneva: International Organization for Migration, 2019.

2 International Organization for Migration. Malaysia. Kuala Lumpur: International Organization for Migration, 2020. https://www.iom.int/ countries/malaysia

3 Department of Statistics Malaysia. Population quick info. Putrajaya: Department of Statistics Malaysia, 2020. https://www.dosm.gov. $\mathrm{my} / \mathrm{v} 1 /$ index.php? $r=$ column/cone\&menu_id=b2RVUmEyZ2ZZYXha UzUrdnpsaWozdz09

4 Department of Statistics Malaysia. Current population estimates Malaysia. Putrajaya: Department of Statistics Malaysia, 2019.

5 Office of the United Nations High Commissioner for Human Rights. The rights of non-citizens. Geneva: United Nations, 2006.

6 Ministry of Home Affairs Malaysia. Statistik pekerja asing terkini mengikut negeri DAN sektor. Putrajaya: Ministry of Home Affairs Malaysia, 2019. http://www.data.gov.my/data/ms_MY/dataset/ statistik-pekerja-asing-terkini-mengikut-negeri-dan-sektor

7 United Nations High Commissioner for Refugees. Figures at a glance in Malaysia. Kuala Lumpur: United Nations High Commissioner for Refugees, 2019. https://www.unhcr.org/en-my/ figures-at-a-glance-in-malaysia.html

8 Chuah FLH, Tan ST, Yeo J, et al. The health needs and access barriers among refugees and asylum-seekers in Malaysia: a qualitative study. Int J Equity Health 2018;17:120.

9 Devadason ES, Meng CW. Policies and laws regulating migrant workers in Malaysia: a critical appraisal. J Contemp Asia 2014;44:19-35.

10 International Organization for Migration. Iom Handbook: protection and assistance for migrants vulnerable to violence, exploitation and abuse. Geneva: International Organization for Migration, 2018.

11 Pocock NS, Suphanchaimat R, Chan CK, et al. Reflections on migrant and refugee health in Malaysia and the ASEAN region. BMC Proc 2018;12:4.
12 Lasimbang HB, Tong WT, Low WY. Migrant workers in Sabah, East Malaysia: the importance of legislation and policy to uphold equity on sexual and reproductive health and rights. Best Pract Res Clin Obstet Gynaecol 2016;32:113-23.

13 Sweileh WM, Wickramage K, Pottie K, et al. Bibliometric analysis of global migration health research in peer-reviewed literature (2000-2016). BMC Public Health 2018;18:777.

14 Villarroel N, Hannigan A, Severoni S, et al. Migrant health research in the Republic of ireland: a scoping review. BMC Public Health 2019;19:324.

15 Khanlou N, Haque N, Skinner A, et al. Scoping review on maternal health among immigrant and refugee women in Canada: prenatal, intrapartum, and postnatal care. J Pregnancy 2017;2017:1-14.

16 Tricco AC, Lillie E, Zarin W, et al. PRISMA extension for scoping reviews (PRISMA-ScR): checklist and explanation. Ann Intern Med 2018;169:467-73.

17 Bay Area Regional Health Inequities Initiative. Framework. Oakland, CA: Bay Area Regional Health Inequities Initiative, 2015. http:// barhii.org/framework/

18 Aromataris E, Munn Z, eds. Joanna briggs institute reviewer's manual. Adelaide, Australia: Joanna Briggs Institute, 2017. https:// wiki.joannabriggs.org/display/MANUAL/JBI+Reviewer\%27s+ Manual

19 National Academies of Sciences, Engineering, and Medicine. A framework for educating health professionals to address the social determinants of health. Washington, DC: The National Academies Press, 2016.

20 Public Health England. Public health outcomes framework 2019/20: a consultation. London: Public Health England, 2019.

21 London School of Hygiene \& Tropical Medicine. Which databases should I search? A guide to the most popular resources. London: London School of Hygiene \& Tropical Medicine, 2014.

22 Bramer WM, Rethlefsen ML, Kleijnen J, et al. Optimal database combinations for literature searches in systematic reviews: a prospective exploratory study. Syst Rev 2017;6:245.

23 Centre for Evidence-Based Medicine. Study designs. Oxford: Centre for Evidence-Based Medicine, 2019. https://www.cebm.net/ 2014/04/study-designs/

24 Tomlin G, Borgetto B. Research pyramid: a new evidence-based practice model for occupational therapy. Am J Occup Ther 2011;65:189-96.

25 Greenacre M. Correspondence analysis in practice. 2nd ed. Boca Raton, FL: Chapman \& Hall/CRC, 2007.

26 Le Roux B, Rouanet H. Multiple correspondence analysis. London: Sage, 2010.

27 Guinto RLLR, Curran UZ, Suphanchaimat R, et al. Universal health coverage in 'One ASEAN': are migrants included? Glob Health Action 2015;8:25749.

28 Zulkifli SN, U KM, Yusof K et al. Maternal and child health in urban Sabah, Malaysia: a comparison of citizens and migrants. Asia Pac J Public Health 1994;7:151-8.

29 Mendelsohn JB, Rhodes T, Spiegel P, et al. Bounded agency in humanitarian settings: a qualitative study of adherence to antiretroviral therapy among refugees situated in Kenya and Malaysia. Soc Sci Med 2014;120:387-95

30 Mendelsohn JB, Schilperoord M, Spiegel P, et al. Is forced migration a barrier to treatment success? similar HIV treatment outcomes among refugees and a surrounding host community in Kuala Lumpur, Malaysia. AIDS Behav 2014;18:323-34.

31 Noh NA, Wahab HA, Bakar Ah SHA, et al. Public health services for foreign workers in Malaysia. Soc Work Public Health 2016;31:419-30.

32 Tanabe M, Myers A, Bhandari P, et al. Family planning in refugee settings: findings and actions from a multi-country study. Confl Health 2017;11:9.

33 Loganathan T, Rui D, Ng C-W, et al. Breaking down the barriers: understanding migrant workers' access to healthcare in Malaysia. PLoS One 2019;14:e0218669.

34 Rahman MM, Arif MT, Safii R, et al. Care seeking behaviour of Bangladeshi migrant workers in Sarawak, Malaysia. Bangladesh Med Res Counc Bull 2019 Jun 15;45:47-53.

35 Chuah FLH, Tan ST, Yeo J, et al. Health system responses to the health needs of refugees and asylum-seekers in Malaysia: a qualitative study. Int J Environ Res Public Health 2019;16:1584.

36 Siah PC, Low SK, Lee WY, et al. Discrimination perceived by child refugees in Malaysia: from the views of representatives from refugees' community service centres and non-government service. Vulnerable Child Youth Stud 2019;18:1-4.

37 Santos A, Ramos HM, Ramasamy G. Musculoskeletal pain among migrant workers in the Malaysian manufacturing industry: the impact of the physical environment, workload and work 
patterns. Pertanika Journal of Social Sciences \& Humanities 2015:23:315-24.

38 Kassim MS, George R, Kassim K, et al. Child abuse and neglect as seen in General Hospital, Kuala Lumpur--a two year study. Med J Malaysia 1989;44:111-21.

39 Jeyakumar $\mathrm{D}$. Thiamine responsive ankle oedema in detention centre inmates. Med J Malaysia 1995:50:17-20.

40 Zabedah MY, Razak M, Zakiah I, et al. Profile of solvent abusers (glue sniffers) in East Malaysia. Malays J Pathol 2001;23:105-9.

41 Osman MT, Al-Naggar RA, Taha BI. Knowledge and awareness of cervical cancer screening among Iraqi immigrant women living in Malaysia. World J Med Sci 2013;8:123-9.

42 Minhat HS, Mustafa J, Sarabi S. Sociodemographic determinants of knowledge on HPV vaccination among Iranian women living in Malaysia. Academic Journal of Cancer Research 2013;6:8-12.

43 Razali S, Salleh RM, Yahya B, et al. Maternal filicide among women admitted to forensic psychiatric institutions in Malaysia: case series. East Asian Arch Psychiatry 2015;25:79.

44 Abdul Rahman S, Jeffree MS, Kamaludin F, et al. Beriberi outbreak among unauthorised immigrants in a detention CAMP in Malaysia. $J$ Immigr Minor Health 2018;20:1294-7.

45 Nwabichie CC, Manaf RA, Ismail SB. Factors affecting uptake of cervical cancer screening among African women in Klang Valley, Malaysia. Asian Pac J Cancer Prev 2018;19:825.

46 Kamaludin NA, How V. The inequality of environmental health awareness among foreign immigrants and local blue-collar workers in Kuala Lumpur, Malaysia. Environ Justice 2016;9:181-7.

47 Woh PY, Thong KL, Lim YAL, et al. Microorganisms as an indicator of hygiene status among migrant food handlers in Peninsular Malaysia. Asia Pac J Public Health 2017;29:599-607.

48 Rajeswari B, Sinniah B, Hussein H. Socio-Economic factors associated with intestinal parasites among children living in Gombak, Malaysia. Asia Pac J Public Health 1994;7:21-5.

$49 \mathrm{Krahl} \mathrm{W,} \mathrm{Hashim} \mathrm{A.} \mathrm{Psychiatric} \mathrm{disorders} \mathrm{in} \mathrm{ASEAN-migrants}$ in Malaysia--a university hospital experience. Med J Malaysia 1998;53:232-8.

50 Chandran PA, Jayaram G, Mahmud R, et al. Microfilaria in hydrocele fluid cytology. Malays J Pathol 2004;26:119-23.

51 Nissapatorn V, Lim YAL, Jamaiah I, et al. Parasitic infections in Malaysia: changing and challenges. Southeast Asian J Trop Med Public Health 2005;36 Suppl 4:50-9.

52 Leong CC. Pre-Employment medical examination of Indonesian domestic helpers in a private clinic in Johor Bahru - an eight year review. Medical Journal of Malaysia 2006;61:592.

53 Sasidharan S, Uyub AM, Azlan AA. Further evidence of ethnic and gender differences for Helicobacter pylori infection among endoscoped patients. Trans R Soc Trop Med Hyg 2008;102:1226-32.

54 Masitah M. Malaria among foreign workers in Selangor, Malaysia. Journal of Health and Translational Medicine 2008;11:53-8.

55 Shailendra S, Prepageran N. Oropharyngeal rhinosporidiosis in a migrant worker: a delayed presentation. Medical Journal of Malaysia 2008;63:65.

56 Chan BTE, Amal RN, Hayati MIN, Noor Hayati MI, et al. Seroprevalence of toxoplasmosis among migrant workers from different Asian countries working in Malaysia. Southeast Asian $J$ Trop Med Public Health 2008;39:9.

57 Farhana F, Jamaiah I, Rohela M, et al. A ten year (1999-2008) retrospective study of amoebiasis in University Malaya medical centre (UMMC), Kuala Lumpur, Malaysia. Tropical Biomedicine 2009;Dec 1;26:262-6.

58 Chan BT, Amal RN, Noor Hayati MI. Comparative study of seroprevalence of toxoplasmosis between local workers and migrant workers in Malaysia. Archives of Medical Science 2009;5:255

59 Murty OP. Cystic tumor of papillary muscle of heart: a rare finding in sudden death. Am J Forensic Med Pathol 2009;30:201-3.

60 Murty OP, Kian CK, Husin MH. Fatal lightning strikes in Malaysia: a review of 27 fatalities. The American Journal of Forensic Medicine and Pathology 2009;30:246-51.

61 Mustafa B, Hani AWA, Chem YK, Mariam M, et al. Epidemiological and clinical features of dengue versus other acute febrile illnesses amongst patients seen at government polyclinics. Med J Malaysia 2010;65:291-6.

62 Su TA, Hoe VCW, Masilamani R, et al. Hand-arm vibration syndrome among a group of construction workers in Malaysia. Occup Environ Med 2011;68:58-63.

63 Ratnasinga J, loras F, Mohd Karee I. Migrant contract workers and occupational accidents in the furniture industry. $J$ Appl Sci 2011;11:2646-51.
64 Ab Rahman AK, Abdullah FH, leishmaniasis V. Visceral leishmaniasis (kala-azar) and malaria coinfection in an immigrant in the state of Terengganu, Malaysia: a case report. J Microbiol Immunol Infect 2011:44:72-6.

65 Taib T, Baba R. Clinical characteristics of patients with leprosy in hospital Kuala Lumpur. Malaysian Journal of Dermatology 2013;31:30-6.

66 Santos A, Ramos HM, Ramasamy G, et al. Prevalence of musculoskeletal pain in a sample of migrant workers in the manufacturing industry in Malaysia. Public Health 2014;128:759-61.

67 Kugan V, Mahadevan DT, Kandasami P, Vijian K, Tata MD, Palayan K. Comparison of features and outcomes of perforated peptic ulcer between Malaysians and foreigners. Med J Malaysia 2016;71:13.

68 Azian MN, Hakim SL, Khadri MS. Leishmaniasis in Peninsular Malaysia: the role of immigrant workers and the vector. Southeast Asian Journal of Tropical Medicine and Public Health 2016;47:607-16.

69 Sahimin N, Lim YAL, Ariffin F, et al. Migrant workers in Malaysia: current implications of sociodemographic and environmental characteristics in the transmission of intestinal parasitic infections. PLoS Negl Trop Dis 2016;10:e0005110.

70 Min NN, Vasudevan SK, Jasman AA, et al. Work-Related ocular injuries in Johor Bahru, Malaysia. International Eye Science 2016:16:416-22.

71 Woh PY, Thong KL, Behnke JM, et al. Characterization of nontyphoidal Salmonella isolates from asymptomatic migrant food handlers in Peninsular Malaysia. J Food Prot 2017;80:1378-83.

72 Ratnalingam V, Umapathy T, Sumugam K. Microbial keratitis in West and East Malaysia. Internal Eye Science 2017;17:1989-92.

73 Noor NM, Shaker MN. Perceived workplace discrimination, coping and psychological distress among unskilled Indonesian migrant workers in Malaysia. International Journal of Intercultural Relations 2017; $57: 19-29$

74 Noordin R, Mohd Zain SN, Yunus MH, et al. Seroprevalence of lymphatic filariasis among migrant workers in Peninsular Malaysia. Trans R Soc Trop Med Hyg 2017;111:370-2.

75 Sahimin N, Lim YAL, Ariffin F, et al. Socio-Demographic determinants of Toxoplasma gondii seroprevalence in migran workers of Peninsular Malaysia. Parasit Vectors 2017;10:238.

76 Labao HC, Faller EM, Bacayo MFD. 'Aches and pains' of Filipino migrant workers in Malaysia: A profile of work-related musculoskeletal disorders. Annals of Global Health 2018;84:474-80.

77 Sahimin N, Douadi B, Yvonne Lim AL, Lim AL, et al. Distribution of Giardia duodenalis (assemblages A and B) and Cryptosporidium parvum amongst migrant workers in Peninsular Malaysia. Acta Trop 2018;182:178-84

78 Jeffree SM, Mihat O, Hassan R, Ahmed K, Safian N, et al. Falciparum malaria outbreak in Sabah linked to an immigrant rubber tapper. Am J Trop Med Hyg 2018;98:45-50.

79 Zerguine H, Tamrin SBM, Jalaludin J. Prevalence, source and severity of work-related injuries among "foreign" construction workers in a large Malaysian organisation: a cross-sectional study. Ind Health 2018;56:264-73.

80 Ya'acob NA, Abidin EZ, Rasdi I, et al. Reducing work-related musculoskeletal symptoms through implementation of Kiken Yochi training intervention approach. Work 2018;60:143-52.

81 Sahimin N, Lim YA, Noordin R. Epidemiology and Immunodiagnostics of Strongyloides stercoralis infections among migrant workers in Malaysia. Asian Pacific Journal of Tropical Medicine 2019 Jun 1;12:250.

82 Jamaiah I, Anuar AK, Najib NA. Imported malaria: a retrospective study in university Hospital, Kuala Lumpur, a ten-year experience. Medical Journal of Malaysia 1998;53:6-9.

83 Sobri M, Merican JS, Nordiyana M. Neuroimaging features of tuberculous meningitis. Medical Journal of Malaysia 2006;61:36-40

84 Daher AM, Ibrahim HS, Daher TM, et al. Health related quality of life among Iraqi immigrants settled in Malaysia. BMC Public Health 2011;11:407.

85 Kwan Z, Pailoor J, Leng Tan L, Tan LL, et al. Leprosy - an imported disease. Lepr Rev 2014;85:170-6.

86 Elmi OS, Hasan H, Abdullah S, et al. Multidrug-Resistant tuberculosis and risk factors associated with its development: a retrospective study. The Journal of Infection in Developing Countries 2015;9:1076-85.

87 William T, Parameswaran U, Lee WK, et al. Pulmonary tuberculosis in outpatients in Sabah, Malaysia: advanced disease but low incidence of HIV co-infection. BMC Infect Dis 2015;15:32.

88 Scheutz F, Heidmann J, Poulsen S. Dental health of Vietnamese boat people on Pulau Bidong, Malaysia. Community Dent Oral Epidemiol 1983;11:255-8. 
89 Levy J. Epidemiological survey of intestinal parasitic infections in children of Sabah, Malaysia. J Public Health 1988;10:240-9.

90 Siah P-C, Lee W-Y, Goh L-Y. Quality of life among refugee children in Malaysia - a brief report. Vulnerable Child Youth Stud 2015;6:1-6.

91 Shaw SA, Ward KP, Pillai V. A group mental health randomized controlled trial for female refugees in Malaysia. American Journal of Orthopsychiatry 2018 Jul 23.

92 Dony JF, Ahmad J, Khen Tiong Y, Tiong YK. Epidemiology of tuberculosis and leprosy, Sabah, Malaysia. Tuberculosis 2004;84:8-18.

93 Vearey J, Orcutt M, Gostin L, et al. Building alliances for the global governance of migration and health. BMJ 2019;366:14143.

94 World Health Organization Regional Office for Europe. Strategy and action plan for refugee and migrant health in the who European region. Copenhagen: World Health Organization Regional Office for Europe, 2016.

95 Reidpath DD, Allotey P. Infant mortality rate as an indicator of population health. Journal of Epidemiology Community Health 2003;57:344-6.

96 Vijayasingham L, Rhule E, Asgari-Jirhandeh N, et al. Restrictive migration policies in low-income and middle-income countries. The Lancet Global Health 2019;7:e843-4.

97 Juárez SP, Honkaniemi H, Dunlavy AC, et al. Effects of non-healthtargeted policies on migrant health: a systematic review and metaanalysis. The Lancet Global Health 2019;7:e420-35.

98 Shao C, Meng X, Cui S, et al. Income-Related health inequality of migrant workers in China and its decomposition: an analysis based on the 2012 China Labor-force dynamics survey data. J Chin Med Assoc 2016;79:531-7.

99 He X, Wong DFK. A comparison of female migrant workers' mental health in four cities in China. Int J Soc Psychiatry 2013:59:114-22.

100 Al-Khatib I, Ju'ba A, Kamal N, et al. Impact of housing conditions on the health of the people at al-Ama'ri refugee cAMP in the West bank of Palestine. Int J Environ Health Res 2003;13:315-26.

101 Mutalip MH, Mishkin K, Paiwai F, et al. Factors associated with sexual intercourse, condom-use, and perceived peer behaviors among adolescents in Malaysia: a school-based cross-sectional study. Malaysian Journal of Social Sciences \& Humanities 2019;4:8-18.

102 Khan MA, Rosly NA, Majeed AB. Knowledge of modes of HIV transmission among public secondary school students in urban and rural areas in Malaysia. Pakistan Journal of Pharmaceutical Sciences 2018;31:1985-90.

103 Mohamad Shakir SM, Wong LP, Lim Abdullah K, Shakir M, Mahavera S, et al. Online STI information seeking behaviour and condom use intentions among young Facebook users in Malaysia. Health Promot Int 2020;35:1116-24.

104 Renzaho AMN, Burns C. Post-migration food habits of sub-Saharan African migrants in Victoria: a cross-sectional study. Nutrition \& Dietetics 2006;63:91-102.

105 Ganle JK, Amoako D, Baatiema L, et al. Risky sexual behaviour and contraceptive use in contexts of displacement: insights from a cross-sectional survey of female adolescent refugees in Ghana. Int J Equity Health 2019;18:127.

106 Bosdriesz JR, Lichthart N, Witvliet MI, et al. Smoking prevalence among migrants in the US compared to the US-Born and the population in countries of origin. PLoS One 2013;8:e58654.

107 Ritchie H, Roser M. Smoking. Oxford: Our World Data, 2019. https://ourworldindata.org/smoking

108 Sweileh WM. Global output of research on the health of international migrant workers from 2000 to 2017. Global Health 2018;14:105.

109 World Health Organisation. Noncommunicable diseases (NCD) country profiles. Malaysia: World Health Organisation, 2018.

110 Zimmerman C, Hossain M, Watts C. Human trafficking and health a conceptual model to inform policy, intervention and research. Soc Sci Med 2011;73:327-35.

111 Zimmerman C, Kiss L, Hossain M. Migration and health: a framework for 21 st century policy-making. PLoS Med 2011;8:e1001034.

112 Par M, Hassan SA, Uba I, et al. Perceived stress among international postgraduate students in Malaysia. Int J Psychol Stud 2015;7:1.

113 Kohno A, Nik Farid ND, Musa G, et al. Factors affecting Japanese retirees' healthcare service utilisation in Malaysia: a qualitative study. BMJ Open 2016;6:e010668.

114 Asits S, Noorhidayah I, Osman A. Migrasi bermusim: Pengaruhnya terhadap kawalan malaria di Sabah. Medical Journal of Malaysia 1999;54:200-9.

115 World Health Organization. A conceptual framework for action on the social determinants of health. Geneva: World Health Organization, 2010.

116 International Organization for Migration. Glossary on migration. 2nd ed. Geneva: International Organization for Migration, 2011.

117 Centre for Cognitive Ageing and Cognitive Epidemiology. Systematic reviews and meta-analyses: a step-by-step guide. Edinburgh: Centre for Cognitive Ageing and Cognitive Epidemiology, 2013. https://www.ccace.ed.ac.uk/research/ software-resources/systematic-reviews-and-meta-analyses

118 Alexander LK, Lopes B, Ricchetti-Masterson K. ERIC notebook. 2nd ed. Chapel Hill: Epidemiologic Research and Information Center, 2015.

119 Cochrane Childhood Cancer. Non-Randomised controlled study (NRS) designs. London: Cochrane Childhood Cancer, 2021. https:// childhoodcancer.cochrane.org/non-randomised-controlled-studynrs-designs

120 Peacock JL, Peacock PJ. Oxford Handbook of medical statistics. Oxford: Oxford University Press, 2011.

121 Moola S, Munn Z, Tufanaru C. Chapter 7: systematic reviews of etiology and risk. In: Aromataris E, Munn Z, eds. JBI manual for evidence synthesis. Adelaide, Australia: JBI, 2017. https://doi.org/ 10.46658/JBIMES-20-08 